\title{
The Evolution of Reliability and Efficiency of Aerospace Bearing Systems
}

\author{
Peter Gloeckner ${ }^{1}$, Charles Rodway ${ }^{2}$ \\ ${ }^{1}$ FAG Aerospace GmbH \& Co. KG, Schweinfurt, Germany \\ ${ }^{2}$ FAG Aerospace Inc., Stratford, Canada \\ Email: peter.gloeckner@schaeffler.com
}

How to cite this paper: Gloeckner, P. and Rodway, C. (2017) The Evolution of Reliability and Efficiency of Aerospace Bearing Systems. Engineering, 9, 962-991. https://doi.org/10.4236/eng.2017.911058

Received: September 9, 2017

Accepted: November 27, 2017

Published: November 30, 2017

Copyright (c) 2017 by authors and Scientific Research Publishing Inc. This work is licensed under the Creative Commons Attribution International License (CC BY 4.0).

http://creativecommons.org/licenses/by/4.0/

\begin{abstract}
The worldwide air traffic underwent a rapid development in recent decades. Between the early 70s and the late 90s of the last century civil air traffic doubled every 15 years. The civil aviation market will continue to grow with $4 \%-5 \%$ each year within the next 20 years. This enormous growth represents major challenges for airframers, engine makers, suppliers, airlines, air traffic management and ground infrastructure. In addition, the public debate on the worldwide civil air traffic is dominated by environmental and climate issues, even though only $2 \%$ of the man-made carbon dioxide $\left(\mathrm{CO}_{2}\right)$ emissions are due to air transportation. Therefore the aerospace industry will have to focus on a low-emission and quite air traffic, and on the conservation of natural resources and our environment. The end-use consumer and environmental policy requirements for aircrafts of the next generation translate into components with improved efficiency and reliability. Rolling bearings are one of these components which significantly determine the reliability and mechanical efficiency of aerospace applications such as aircraft and rotorcraft engines and transmission systems. They have to withstand very demanding operating conditions. Especially main shaft bearings in modern aircraft engines experience high rotational speeds and temperatures. Furthermore aerospace bearings have to meet the highest reliability standards and require low-weight design solutions. These operating conditions and requirements present a continuous challenge for improvements in all fields of bearing technology. This article presents solutions in aspects of materials, design, analysis, and surface technologies in order to meet the environmental, reliability, and economical requirements of advanced aerospace bearing systems. State of the art bearing analysis and advanced bearing design solutions contributing to lower friction power losses and increased systems efficiency are discussed. Weight, functional, and maintenance benefits are presented with the example of highly integrated aircraft engine main shaft bearings. It is also shown that the progress in bearing materials and surface technology devel-
\end{abstract}


opment is the basis for weight and friction energy reduction in aerospace bearing systems.

\section{Keywords}

Rolling Element Bearings, Aviation, Environment, Friction, Efficiency, Aircraft Engines, Helicopter

\section{Introduction}

Today's world aircraft fleet consists of 20,000 airplanes in service. Considering a projected $4 \%$ - 5\% growth per annual passenger kilometer and an estimated fleet replacement of $40 \%$ until the year 2035 , the world airplane fleet will double to a total amount of approximately 40,000 aircraft. Main drivers for the predicted growth are Asian-Pacific and Middle-Eastern markets. Associated with the high growth rate are environmental challenges demanding reduced fuel burn and emissions.

It is well established that emissions generated due to air transportation such as carbon dioxide $\left(\mathrm{CO}_{2}\right)$ and water vapor $\left(\mathrm{H}_{2} \mathrm{O}\right)$ act as greenhouse gases. Since the year 1990 the kerosene consumption decreased by $70 \%$ and the $\mathrm{CO}_{2}$ emissions due to air transport decreased by $30 \%$ per passenger kilometer within the last 20 years. With regards to the fast growing air transport market, the worldwide absolute $\mathrm{CO}_{2}$ emissions due to air transportation increased from 400 million tonnes in 1990 to more than 600 million tonnes in 2005. Thus, carbon-neutral growth and rather total $\mathrm{CO}_{2}$ emission reduction is required in order to limit the share of man-made carbon emissions to $3 \%$ in the year 2050 .

Nitrogen oxides ( $\mathrm{NO}$ and $\mathrm{NO}_{2}$, collectively termed $\mathrm{NO}_{\mathrm{x}}$ ) are suspect to produce ozone $\left(\mathrm{O}_{3}\right)$ in the upper troposphere, influencing the hydroxyl radical $(\mathrm{OH})$ budget, the main determinant of the oxidizing capacity of the atmosphere and therefore increase the destruction of methane $\left(\mathrm{CH}_{4}\right)$, which also is a greenhouse gas [1]. It is still object of research and not fully understood under which conditions the positive radiative forcing from increased $\mathrm{O}_{3}$ and the negative radiative forcing from reduced $\mathrm{CH}_{4}$ equal each other [2] [3]. One global aircraft scenario by [2] for a 2050 atmosphere even predicts that methane would be about $5 \%$ less than that calculated for without aircraft.

Line shaped contrails can be estimated to cover $0.1 \%$ of the earth's surface (regionally $3 \%-5 \%$ ) and are a consequence of the crystallization process in the exhaust of a jet engine. Hydrocarbons $(\mathrm{HC})$, sulfur dioxide $\left(\mathrm{SO}_{2}\right)$, water vapor $\left(\mathrm{H}_{2} \mathrm{O}\right)$, soot in the exhaust and the exhaust temperature itself determine the contrail generation. They are predicted to cover roughly $0.5 \%$ of the earth's surface by the year 2050 per scenarios described in [2]. [4] concluded that line shaped contrails have a limited effect on the earth's climate, i.e. their influence on surface warming and precipitation is very limited. However, various studies have shown 
that aviation-induced cirrus are generated either via contrails spreading out or by injection of aerosols into the upper troposphere to provide ice nuclei that may subsequently form the cirrus clouds [5] whose areal coverage may be significantly greater than linear contrails. It cannot be $100 \%$ excluded that cirrus clouds would form in the absence of aviation activity, but the spatial coherence of the contrail-induced cirrus strongly suggests that the cirrus cloud is of aviation origin [5]. The mechanisms associated with increases in cirrus cover are not well understood and need further investigation [2]. The predicted future impacts on the earth's radiative forcing are shown in Figure 1.

From Figure 1 it is obvious that the aviation industry has to focus both on emission reduction and enhancement of understanding the effect of aviation on the atmosphere.

In order to comply with the challenges connected to a fast growing market and emission effects on the earth's climate as described above, the European Commission described in their vision "Flightpath 2050" the economical, social and environmental goals for the European aviation in the year 2050 [6]. Examples of these goals are reductions of $75 \% \mathrm{CO}_{2}, 90 \% \mathrm{NO}_{x}$, and $65 \%$ noise compared to capabilities of typical new aircraft in 2000. Furthermore it needs to be noted that currently approximately one third of an airline's total operating costs are contributed by kerosene costs.

These challenges are handled by airframers, engine makers and suppliers through technical innovations on the one side. The use of sustainable alternate fuels will be followed by both the manufacturers and airlines, while air traffic and energy

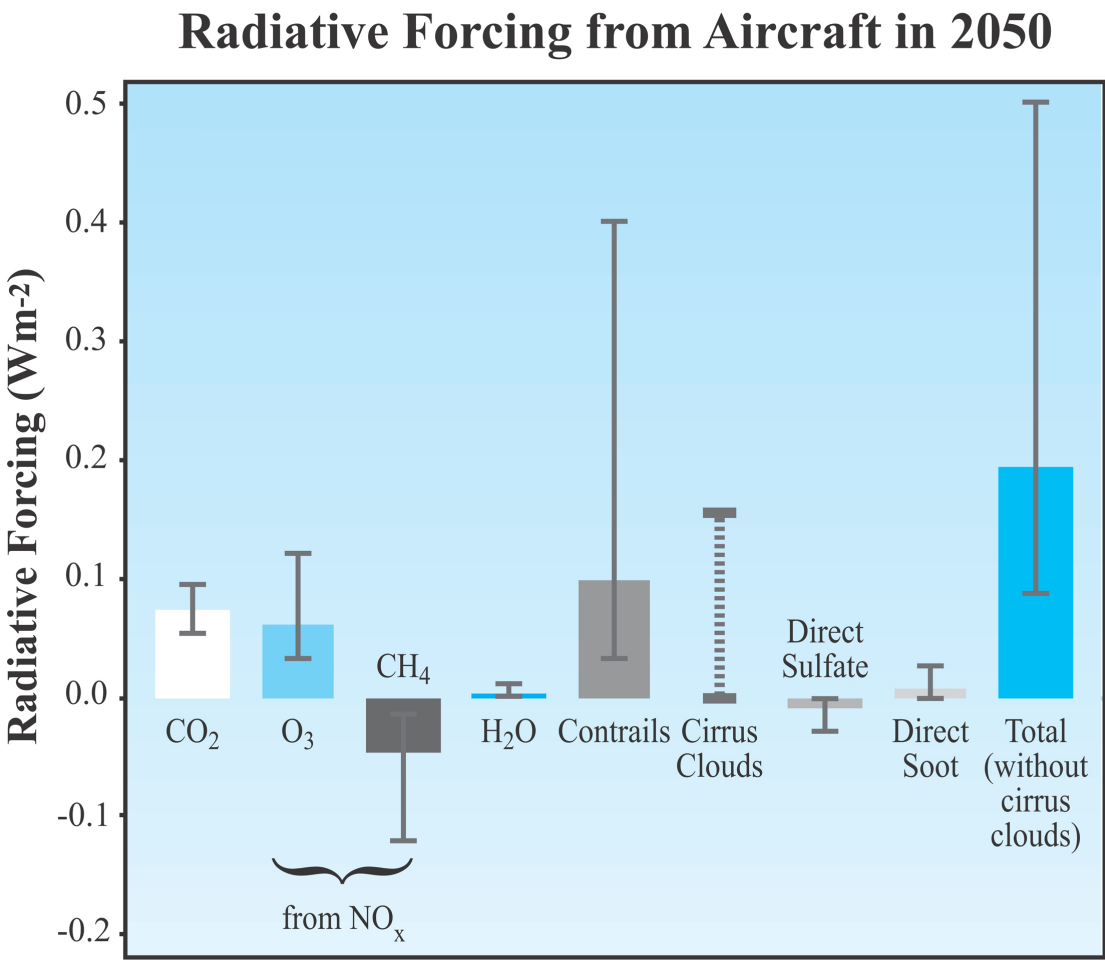

Figure 1. Radiative forcing from aircraft in 2050 (from [2]). 
management and ground infrastructure development is one of the key tasks for airlines, aviation authorities and ground transportation companies on the other side.

In the following chapter new environmental friendly aircraft systems concepts and the derived requirements to aerospace sub-systems are presented.

\section{Current and Future High Efficient Aircraft Systems}

In this chapter new fixed and rotor wing developments, aircraft engine and drive train solutions and their impact on aerospace bearing development are discussed. It is evident that aircrafts and propulsion systems cannot be examined isolated, but in its interaction of aerodynamics, structure and thermodynamics of fuselage, wings, and propulsion.

\subsection{Aircraft Developments}

Decreased fuel burn and emissions, noise reduction, and increased passenger quantity for unchanged fuselage dimensions are the main drivers for fixed wing aircraft developments. One key for improvements in aerodynamics is the reduction of friction and lift-dependent drag. Advances in materials, structures and aerodynamics currently enable significant lift-dependent drag reduction by maximizing effective wing span extension.

Various wing configurations such as the narrow delta, broad delta, box wing (Figure 2), and blended or flying wing (Figure 3 ) are currently investigated expecting radical improvements.

Significantly contributing to a low emission and low noise aircraft is the development and use of light-weight and higher strength materials, the introduction of advanced manufacturing techniques and flight control systems. Starting with pure metal passenger aircrafts 50 years ago, the composite materials and advanced alloys content increased continuously. For example airplanes introduced in the 1990 s were featuring $12 \%$, in the 2000 s $25 \%$, and recent aircraft

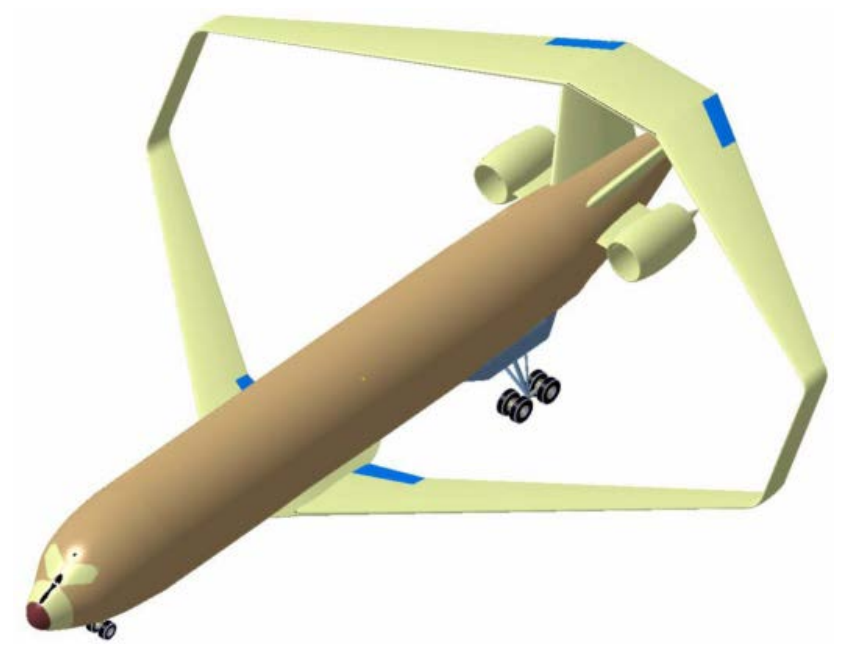

Figure 2. Box wing concept (from [7]). 


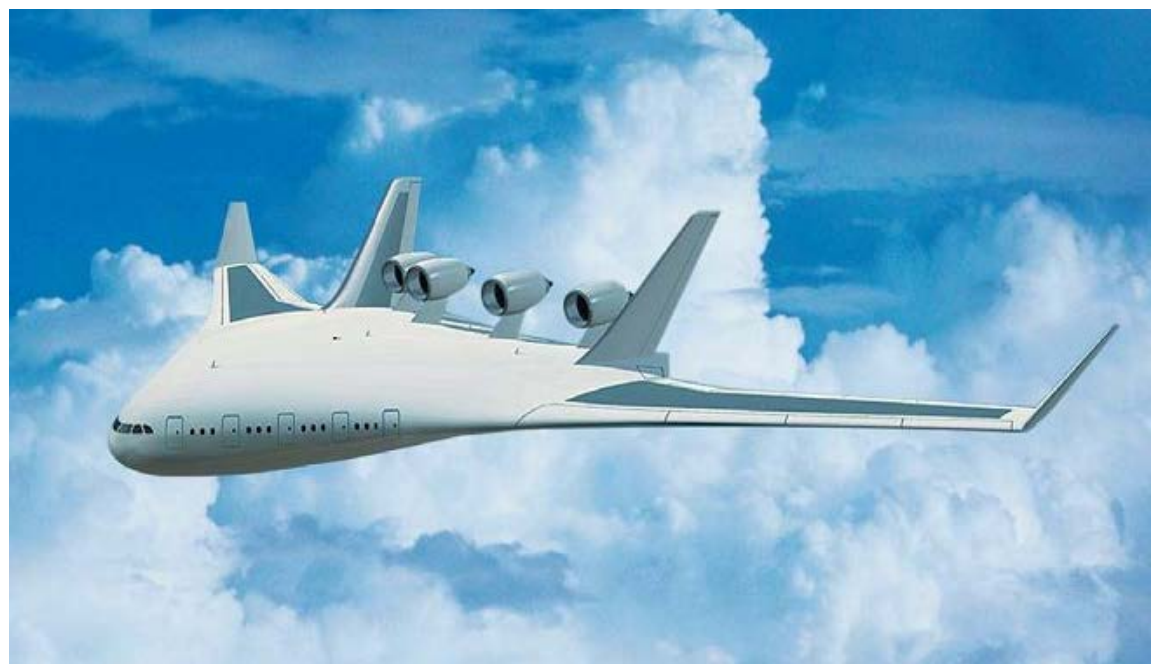

Figure 3. Blended wing concept (from [8]).

developments (Boeing 787, Airbus A350, Bombardier C-Series, etc.) have a content of more than $50 \%$ of composite/advanced materials.

Associated with the development and serial introduction of advanced materials are innovative manufacturing techniques including advanced welding technologies such as: laser beam, electron beam, and friction stir welding. These innovations remove the need for traditional rivets, reducing aerodynamic drag, lowering manufacturing costs, and decreasing aircraft weight.

These development trends do not solely apply to fixed-wing aircrafts, but to rotary wing aircrafts as well. Emphasis of rotorcraft development, of course, slightly differs with the key goals improved range, payload, higher velocity and reduced overall noise. While the mass transportation sector is served by the fixed-wing aircraft industry, search and rescue and business transportation will require faster, quieter and more fuel efficient short and mid-term transportation capabilities. The tilt rotor (Figure 4) represents one solution to these requirements competing with ultra-high speed trains.

Furthermore high-speed flight and developments in unmanned and autonomous flight may extend beyond fixed wing versions into the rotorcraft field, with military demonstrators already existing. Such systems would supplement unmanned fixed wing aircraft already used for surveillance and ground attack providing hover capability.

It should be noted that the trend to a more electric aircraft-already started with the introduction of electrical power systems for engine starts, cabin pressurization, flight-control actuation, and wing ice-protection-will continue the next decades. In addition to the replacement of existing hydraulic and pneumatic systems, the aerospace industry is looking at new systems, such as autonomous taxiing and icing detection in order to reduce fuel burn and increase flight safety. Electric taxiing systems using electric motors on the main landing gear wheels, which also could retrofit current wheels, were already successfully tested. The electric motors themselves are powered by the auxiliary power unit (APU), which could 


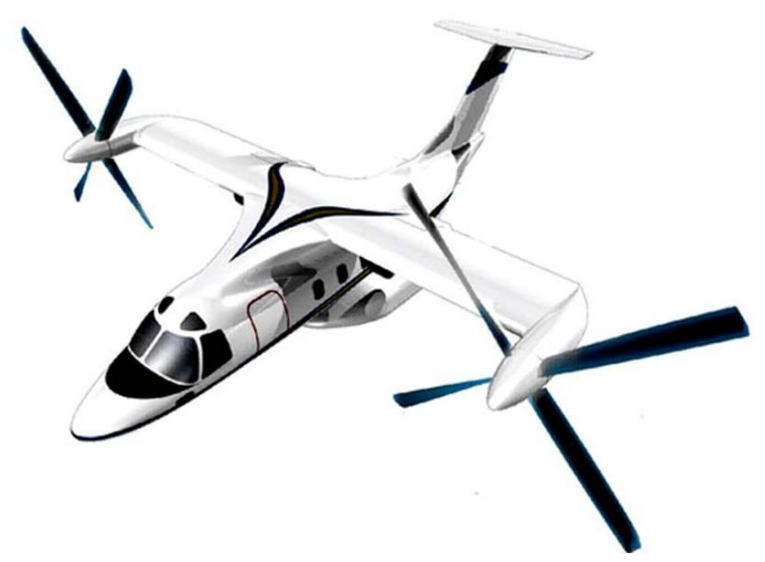

Figure 4. Tilt rotor aircraft concept.

be replaced by fuel cells in order to decrease fuel burn and emissions. Electric or hybrid propulsion, as it is known from automotive applications, might be close to enter service in light aircraft and helicopters. Small size and short range helicopter could use electric motors as engine back-up system. In case of an engine failure, the electric motor would prevent the main rotor speed from dropping. Also, all-electric small size helicopters and lightweight motor glider were tested with success.

These activities cover all aircraft and aircraft sub systems. However, medium and large aircraft propulsion will not be affected by significant increased electrification in the near future.

\subsection{Propulsion and Drive Train Developments}

The developments of new aircraft engines for passenger aircraft have to meet the requirements of decreased fuel burn and lower emissions. Per one kilogram fuel (kerosene) approximately $3.2 \mathrm{~kg} \mathrm{CO}_{2}, 1.3 \mathrm{~kg} \mathrm{H}_{2} \mathrm{O}, 15 \mathrm{~g} \mathrm{NO}_{\mathrm{x}}$ and $1 \mathrm{~g} \mathrm{SO}_{\mathrm{x}}$ are produced by current state of the art jet engines. Moreover, $\mathrm{CO}$, unburned hydrocarbons, and particulates are emitted. Keys to increase the overall gas turbine efficiency are higher thermal, propulsive and combustion chamber efficiencies. One way to increase the thermal efficiency of an aircraft gas turbine is to allow for higher turbine inlet temperatures (TIT), Figure 5. This, however, directly impacts $\mathrm{NO}_{\mathrm{x}}$ emissions, which increase with both pressure and temperature. Besides this trade-off with $\mathrm{CO}_{2}$ emissions, the TIT increase is limited by the strength of current and future turbine stage materials. With higher turbine inlet temperatures the cold section of the engine including the rolling bearings in the near surrounding will experience higher external thermal load as well.

Due to the remarkable progress in gas turbine combustor technology, the aircraft engine $\mathrm{NO}_{\mathrm{x}}$ emission could be lowered significantly throughout the last decades. While today's engines feature annular combustion chambers which contribute to the major portion of the savings, new developments such as RQL systems (rich burn, quick quench, lean burn), and staged-DLI (direct lean injection) combustors applied in the next generation aircraft gas turbines predict further 


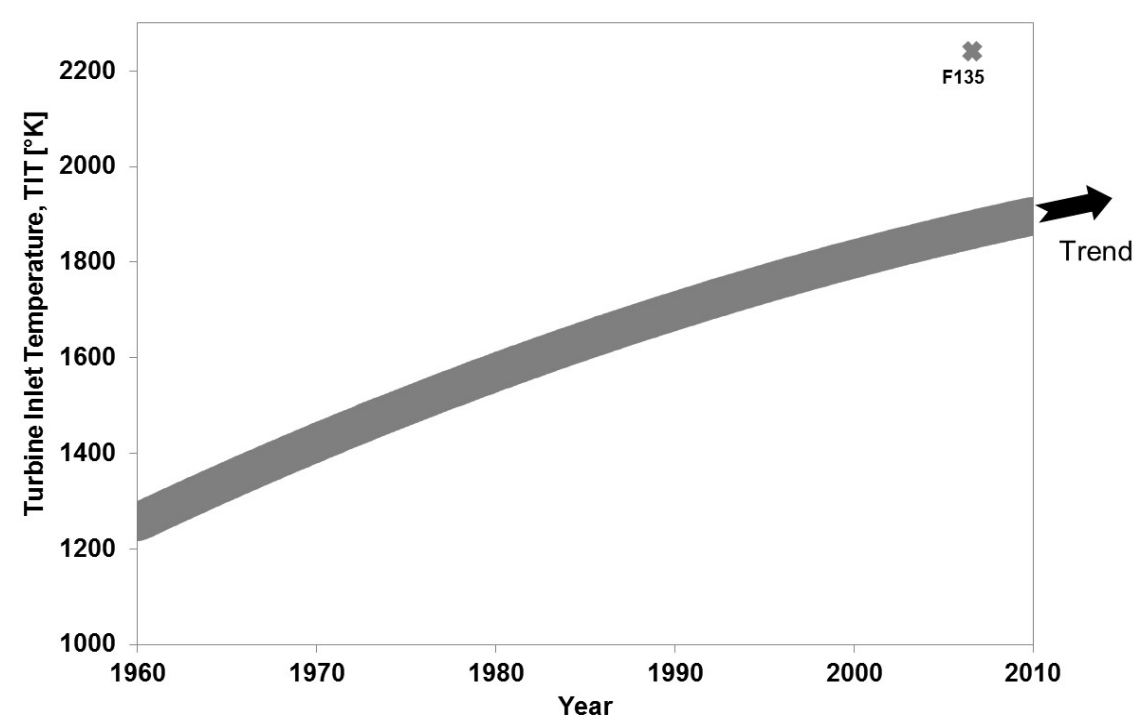

Figure 5. Turbine inlet temperature (TIT) development.

substantial $\mathrm{NO}_{\mathrm{x}}$ reductions. $\mathrm{RQL}$ combustors control $\mathrm{NO}_{\mathrm{x}}$ production through a series of changes to the air to fuel ratio as the combustion air progresses through the combustor. For staged-DLI combustors, the $\mathrm{NO}_{\mathrm{x}}$ control is being achieved by switching (staging) between pilot and main burner zones arranged in concentric circles. RQL combustors appear likely to meet the ICAO's Comittee on Aviation Environmental Protection (CAEP) mid-term goal $\left(\mathrm{NO}_{\mathrm{x}}\right.$ reduction in 2016: $45 \% \pm 2.5 \%$ below CAEP/ 6 at OPR 30), but the long-term goal (2026 at $60 \% \pm$ $5 \%$ below CAEP/6 also at OPR 30) may not be achievable particularly for high OPR engines. Dramatic reductions in $\mathrm{NO}_{\mathrm{x}}$ production from the use of new generation staged DLI combustors were shown recently, although the migration towards the long-term goal is not expected in the short-term.

Higher jet engine propulsive efficiencies are achieved by increasing the bypass ratio (BPR). In addition higher bypass ratios positively influence the noise level. Reduced noise levels are connected with lower airport noise fees, potential curfew flexibility, and an enhanced take-off and departure routing flexibility (preferred runways, more direct flight paths), which has a direct benefit to reduced fuel burn and therefore $\mathrm{CO}_{2}$ emissions. Throughout the last decades the BPR increased considerably helping to achieve the reduced fuel burn per passenger as described above. Figure 6 shows the bypass ratio development (for medium and large size turbofan engines having a take-off thrust rating greater than $80 \mathrm{kN}$ ) with bypass ratios as low as 4 in the 1970s and engines having BPR above 12 as of today.

The fuel burn and emission reduction as well as noise requirements demand further increases in BPR. Technologies in order to achieve these goals are the advanced high bypass ratio (HBR) turbofan, the geared turbofan, the ultra-high bypass ratio (UHBR) turbofan and the Open Rotor or Unducted Fan (see Figure 7). HBR turbofans and geared turbofans, which are already in service, have BPRs 


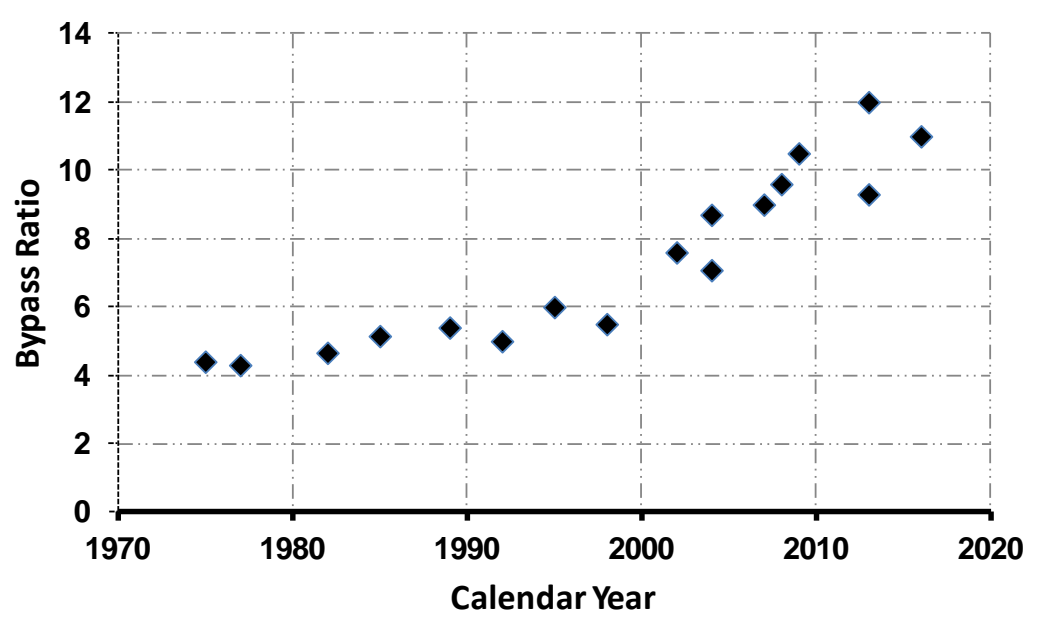

Figure 6. Bypass ratio (BPR) development.

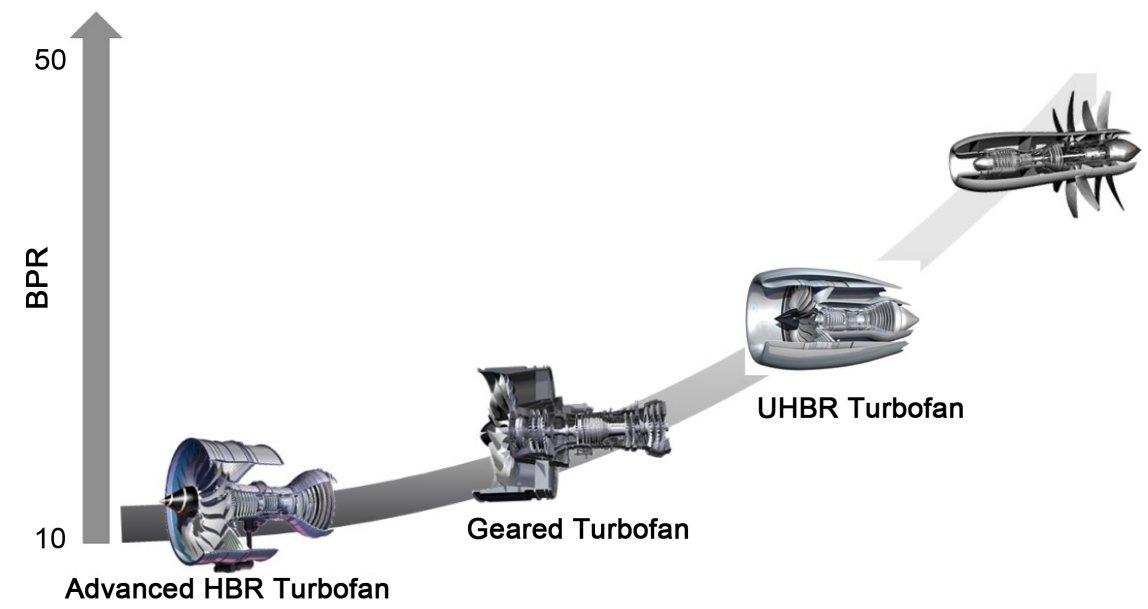

Figure 7. High bypass ratio (HBR) technologies.

of approximately 10. The UHBR turbofans require further development jumps especially with regards to the power gearbox enabling BPRs of 20 and a high speed low pressure turbine. Revolutionary designs such as the Open Rotor Concept will feature counter rotating spools within a power gearbox.

The fan drive reduction gear system utilized in the geared turbofan technology enables increased BPR due to decreased fan speed and implies the benefit of a high speed low pressure turbine. Thus, the number of low pressure turbine stages can be decreased and therefore leads to reduced engine length, weight and cost. The additional weight of the fan reduction gear system is more than off-set by the reduced low pressure turbine weight. The larger the fan diameter the higher the power to be transferred to the reduction gearbox, ranging up to 40 000 shaft horsepower. This requires large scale and highly loaded bearings in the gearbox, especially challenging bearing material and internal design. These challenges are intensified by the introduction of the UHBR and Open Rotor aircraft engines. Here large scale counter rotating rolling bearings are required representing major challenges in manufacturing techniques, design and lightweight optimiza- 
tion.

\section{Requirements for High Efficient Rolling Bearings for Aerospace Applications}

Main shaft bearings in jet engines experience high rotational speeds and temperatures. The bearing speed index, the product of the bearing's pitch diameter and the rotational speed, $\mathrm{D} \times \mathrm{N}$, provides information about the centrifugal forces and the sum velocity acting on the rolling contact. As there has always been the need to increase the thrust to weight ratio and in parallel to lower the specific fuel consumption, main shaft speeds and gas temperatures increased steadily since jet engines have been in use. Today, jet engine main shaft bearings operate at speed indices of up to $\mathrm{DN}=3.5 \times 10^{6} \mathrm{~mm} / \mathrm{min}$ (cf. Figure 8).

In contrast to the demanding operating conditions longer service lives, higher reliability and efficiency is required.

Typical failure rate requirements for modern engines are:

- One unscheduled engine removal (UER) is allowed every 1 Million operating hours of the entire engine fleet in service, i.e. UER's $<1 \mathrm{ppm}$.

- In-flight shut downs (IFSD). This may only happen once every 4 Million operating hours, i.e. IFSD $<0.25 \mathrm{ppm}$.

These reliability goals apply to all engine components and therefore also for the rolling bearings. Rolling bearings in accessory engine and helicopter gearboxes have to deal with high loads and at the same time, require low-weight design solutions. Both gearbox and main shaft bearings in the aero engine and helicopter sector have to proof reliability during negative acceleration which results into operation without oil.

The challenging operating conditions require completely different materials, analysis and calculation methods, designs, and manufacturing technologies compared to the first generation of aerospace bearings. Furthermore rolling bearings in aircraft engines, but also in helicopter transmissions, significantly influence

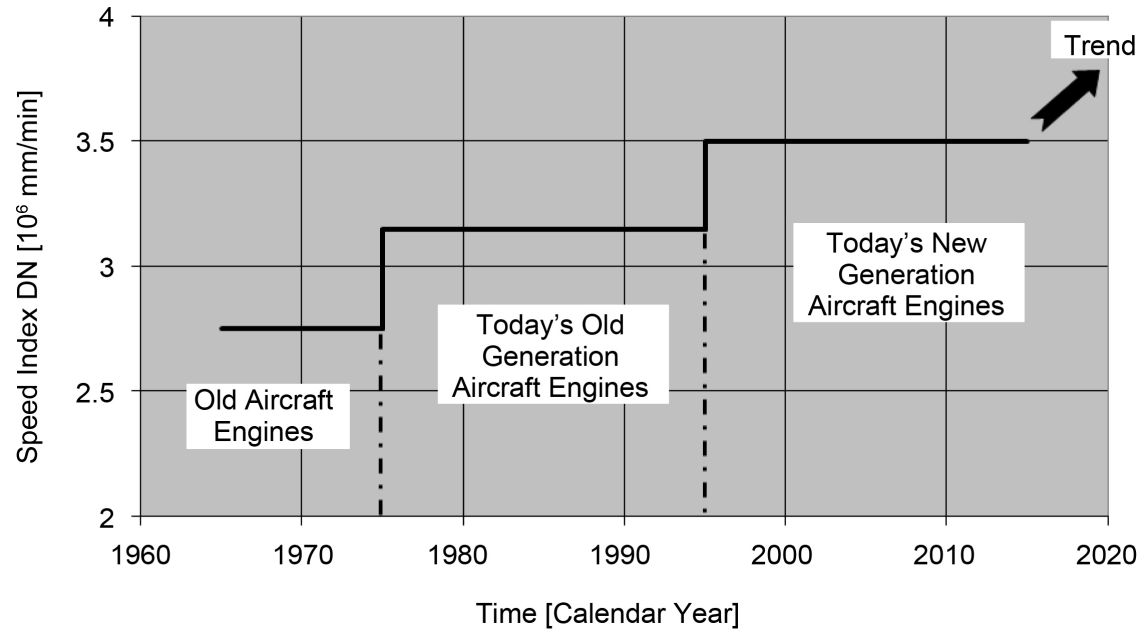

Figure 8. Speed index for main shaft aircraft engine bearings. 
the overall mechanical engine/gearbox efficiency and therefore play a key role in reducing fuel consumption and emissions as well as bearing and system weight and life cycle cost.

\section{High Speed Bearing Analysis}

The occurring high rotational speeds in aerospace bearings require improved design tools to consider high speed kinematics and high speed contact mechanisms. Rolling element centrifugal forces can be of significant amount and must not be neglected in the high speed bearing design process. Besides increasing contact load, the centrifugal forces within a ball bearing lead to different inner and outer race contact angles as shown in Figure 9.

In high speed roller bearings for instance, the larger contact deformations caused by the higher contact loading on the outer ring raceway is similar to an increased radial clearance which can lead to increased maximum roller loading as a consequence of a less extended contact zone [9].

The bearing internal velocities and the rolling contact stressing including the fluid film build up between raceway and rolling element and therefore the friction and temperature in the contact zone are significantly affected by high speed operating conditions. Especially high speed ball bearings experience significant amounts of dissipated energy in the rolling contacts and therefore require large amounts of oil supplied by either side jet or under-race lubrication (cf. Paragraph 6). Depending on speed, load, lubrication condition, and bearing size, the power loss generated in an aircraft engine core thrust bearing can be greater than $35 \mathrm{~kW}$ [10] [11] and therefore significantly contributes to the total mechanical power losses in an aircraft engine.

In order to be able to calculate the rolling contact stresses and contact angles, the bearing internal loads and velocities need to be known. For that and many other purposes rolling bearing analysis tools have been developed throughout the last decades to comprehensive programs considering not only the rolling

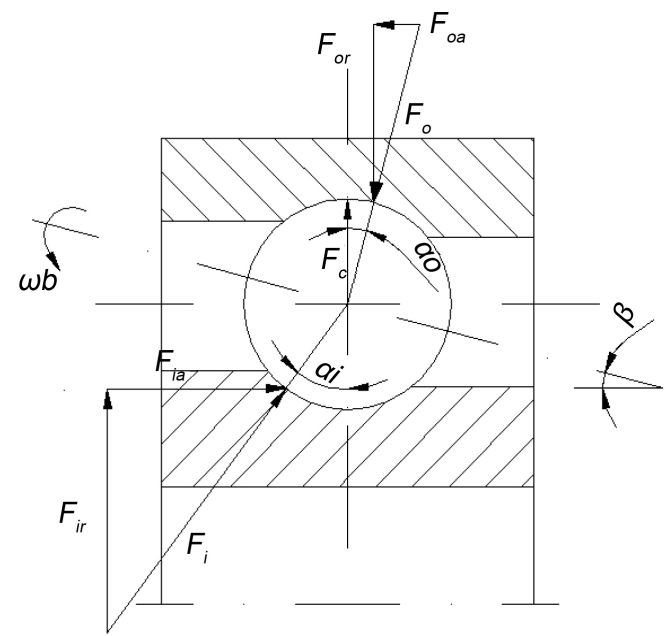

Figure 9. High speed ball bearing kinematics. 
bearing itself, but also other, the bearing performance influencing machine elements such as shafts, gears and housings.

Figure 10 shows the bearing contact stress between the outer race and the rolling elements for a shaft-gear-bearing-system by using the bearing analysis tool BEARINX. Based on the shaft-bearing arrangement and the operating conditions like gear loads, inner/outer ring rotational speeds, temperature of shaft and housing, the analysis is performed. Even roller profiles and surface roughness topography (beyond simply Ra values) can be considered. Calculation results for the shaft-gear-bearing system such as deflections and bearing loads as wells as results for each single rolling bearing like rolling element load, contact stress distribution and deformations are obtained. These values are the basis for further detailed calculations of the contact oil film thickness and factored rolling bearing life. This (quasi-static) bearing analysis method provides an excellent way to design the internal bearing geometry in a short period of time.

For some bearing applications it is necessary also to know the dynamic behavior of the bearing. For example, rolling element rotational speed in the orbit, rotational axis of the rolling element, micro slippage between rolling element and race, skidding of the entire bearing, cage speed and cage loads can be determined using a dynamic rolling bearing software. In the 1990s ADORE ${ }^{\oplus}$ developed by Gupta [12] was one of the first available programs to calculate the internal bearing behavior. With the improved understanding of the rolling contact behavior within the last 20 years-boosted by the fast growing computing power-it was also possible to refine and design dynamic bearing tools that are more comprehensive. One state of the art analysis tool used in the design process is CABA3D [13].

For instance, roller motion (skewing), rolling element speed, and cage loads, e.g. of planetary spherical roller bearings (Figure 11) can be calculated with this advanced tool. Based on this, the optimum cage design can be engineered.

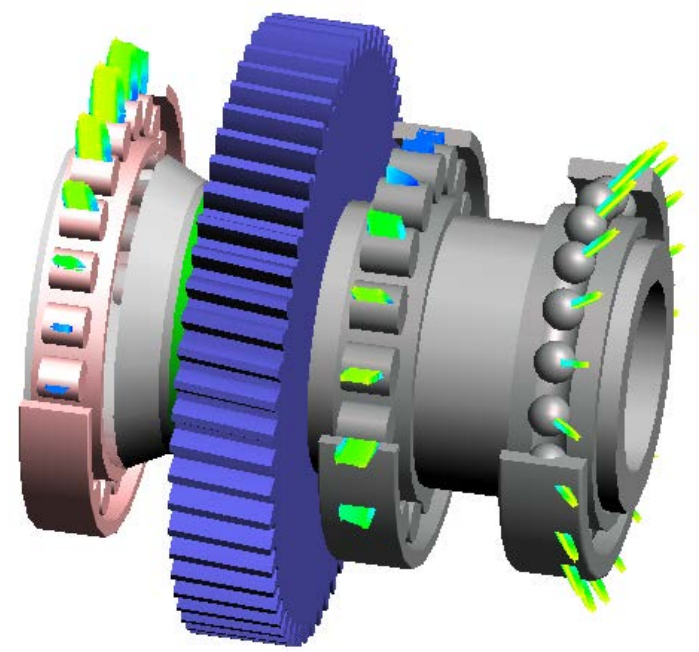

Figure 10. Contact stress between rolling elements and outer rings in a shaft-gear-bearing analysis model. 


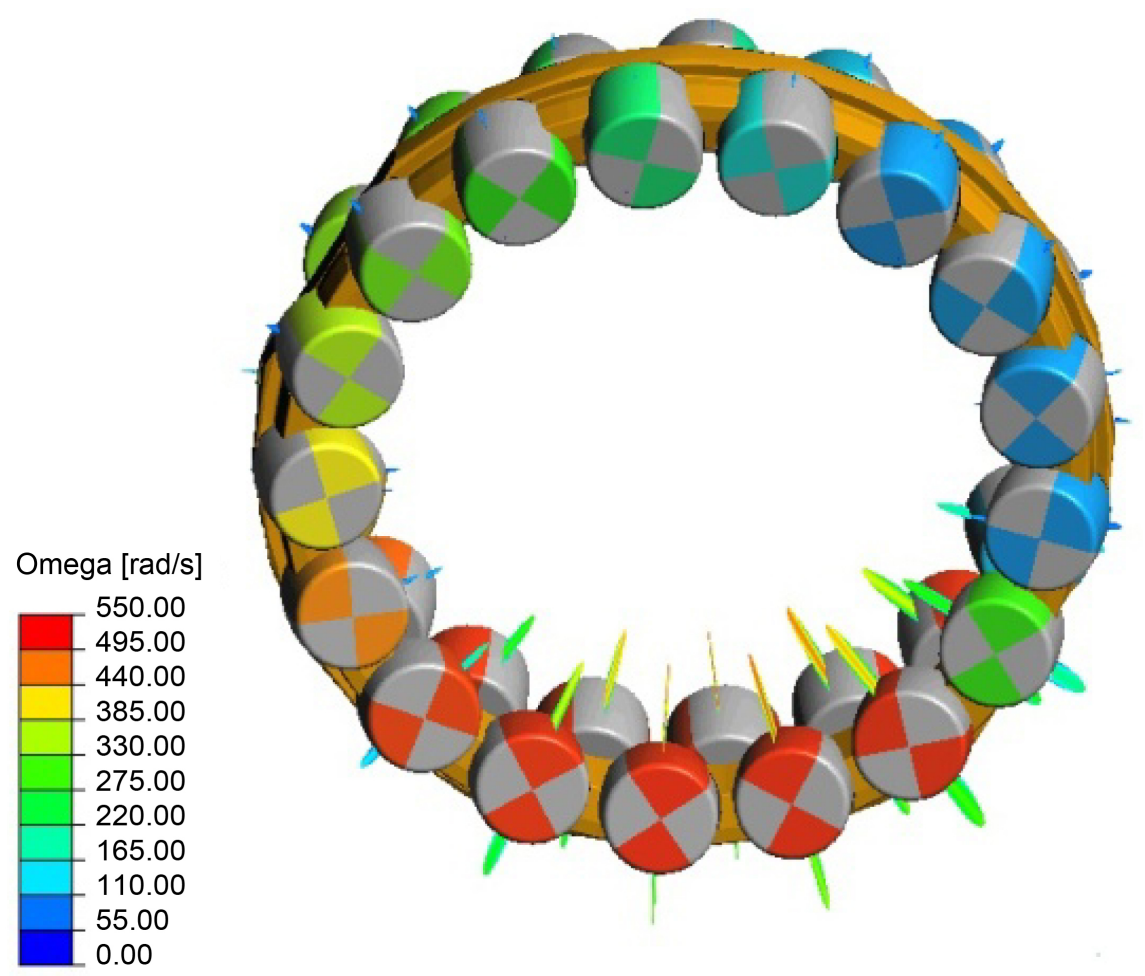

Figure 11. Roller angular velocity of a spherical roller bearing.

Another analysis focus is the contact mechanic itself. To develop both quasi-static and dynamic analysis methods, it is necessary to understand the behavior in the rolling contact. After the development of the EHL-theory by Hamrock and Dowson in the 1970s, tremendous progress has been made in the field of rolling contact analysis, supported by faster computers and sophisticated numerical solution methods. Starting with purely isothermal models [14], the thermal analysis of fully flooded or starved large elliptical contacts is possible today (Figure 12). The thermal EHL theory is therefore a suitable method in order to predict rolling contact friction and power loss, to understand experimental investigation results, and to investigate high speed bearing phenomena, such as the phenomenon of micro-sliding, occurring in high speed ball bearings. Micro-sliding-as a result of the changing effective radii following a certain raceway curvature within the major axis of the contact ellipse-leads to additional contact friction heat as described by [15]. This means in respect to rolling contact calculation, thermal effects have to be considered (Gloeckner et al. [16]). Figure 12 shows the temperature distribution in the middle of the oil film for a fully flooded inner race/ball EHL-contact with ideally smooth surfaces. The temperature peaks are a consequence of oil inlet compression $(\mathrm{x} / \mathrm{a}=-1)$, contact friction due to sliding $(\mathrm{x} / \mathrm{a} \approx 0)$ and oil outlet expansion $(\mathrm{x} / \mathrm{a}=1)$.

The high contact temperatures translate into very thin oil films requiring an excellent raceway surface finish. This is achieved by a special super finishing of the races and rolling elements resulting in reduced friction power generated in 


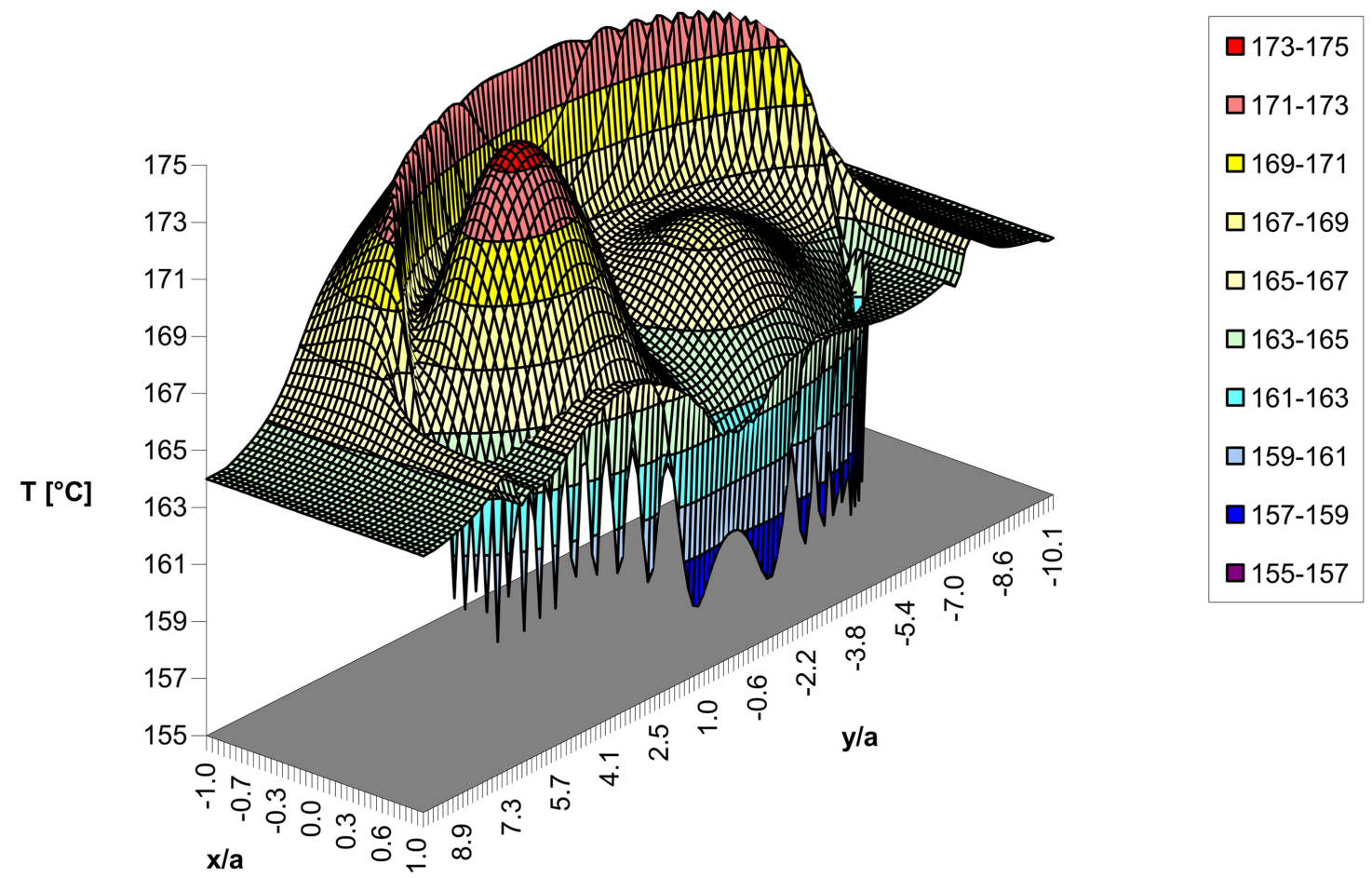

Figure 12. EHL-temperature distribution.

the rolling contact. However, a complete separation of raceway and rolling element by the lubricant does not represent the actual contact behavior. The film thickness parameter $\lambda$, the quotient of minimum oil film thickness and the combined root mean square surface roughness of rolling element and raceway, is typically used for evaluating the level of separation between the contacting bodies for rolling bearings. Even for film thickness parameters of $\lambda>3$, asperity contacts cannot be excluded during operation (Salpistis [17]) and a bearing life reduction can be the result (Harris [9]). In addition particle indentations by contaminated oil are of significant influence to bearing life (Ebert [18]) and typically lead to a spalling of the distressed surface. The omnipresent risk of particle indentations and increasing jet engine shaft speeds require optimized contact geometries, i.e. raceway curvatures, and demand new materials and surface technologies such as Duplex Hardening (cf. Paragraph 5).

Transient elastohydrodynamic calculations are also in the focus of bearing design. For instance the transition from the unloaded zone into the loaded zone in radially loaded bearings can be calculated or the contact behavior during the cycling of an indentation can be simulated. Considering a certain asperity profile and calculations in the mixed friction regime are the latest state of development. Current bearing life calculation is based on semi-empirical formulas. Understanding the real contact stressing, i.e. the contact behavior under consideration of asperity contacts in the (thermal) mixed friction regime for large elliptical contacts, would promote more real physics-based bearing life and friction prediction models. 


\section{Materials and Surface Technologies for High Efficient Aerospace Bearing Systems}

Based on the continuously increasing rotational speeds and temperatures in aircraft engine main shaft bearings (see Figure 8), bearing steels must combine both a high hot hardness and a good rolling fatigue cycling strength. Therefore special bearing materials dedicated to aerospace use were developed starting in the 1960s (Figure 13).

The introduction of the through-hardened high-speed tool steel M50 (80 MoCrV 4216, AMS 6491) at that time enabled higher shaft speeds and therefore improved aircraft engine efficiency. Simultaneously, increased reliability requirements called for purer steels with a lower content of detrimental inclusions. An increased bearing steel cleanliness was achieved by the introduction of the VIM-VAR (vacuum induction melting followed by one or more vacuum arc remelting process steps) steel making process for aerospace bearing steels in the 1970s. Shortly after the VIM-VAR process introduction, case carburized bearing steels such as RBD (X20WCr10) and the further development of the M50, the M50NiL (13MoCrNiV 4216, AMS 6278), were used in first aerospace applications. Case carburized materials have been established during the last decades as the preferred option for bearings on the high speed shaft of aircraft engines, due to the ability to hamper or even stop crack growth in the race caused by tension stresses. The development of M50NiL represents a further leap in bearing steel development, because of its capability to develop residual compressive stresses in the hardened layer (case) [19]. Optimized compressive residual stresses in the case on the one hand lead to reduced subsurface stresses (material stressing, [20]) and on the other hand hinder crack

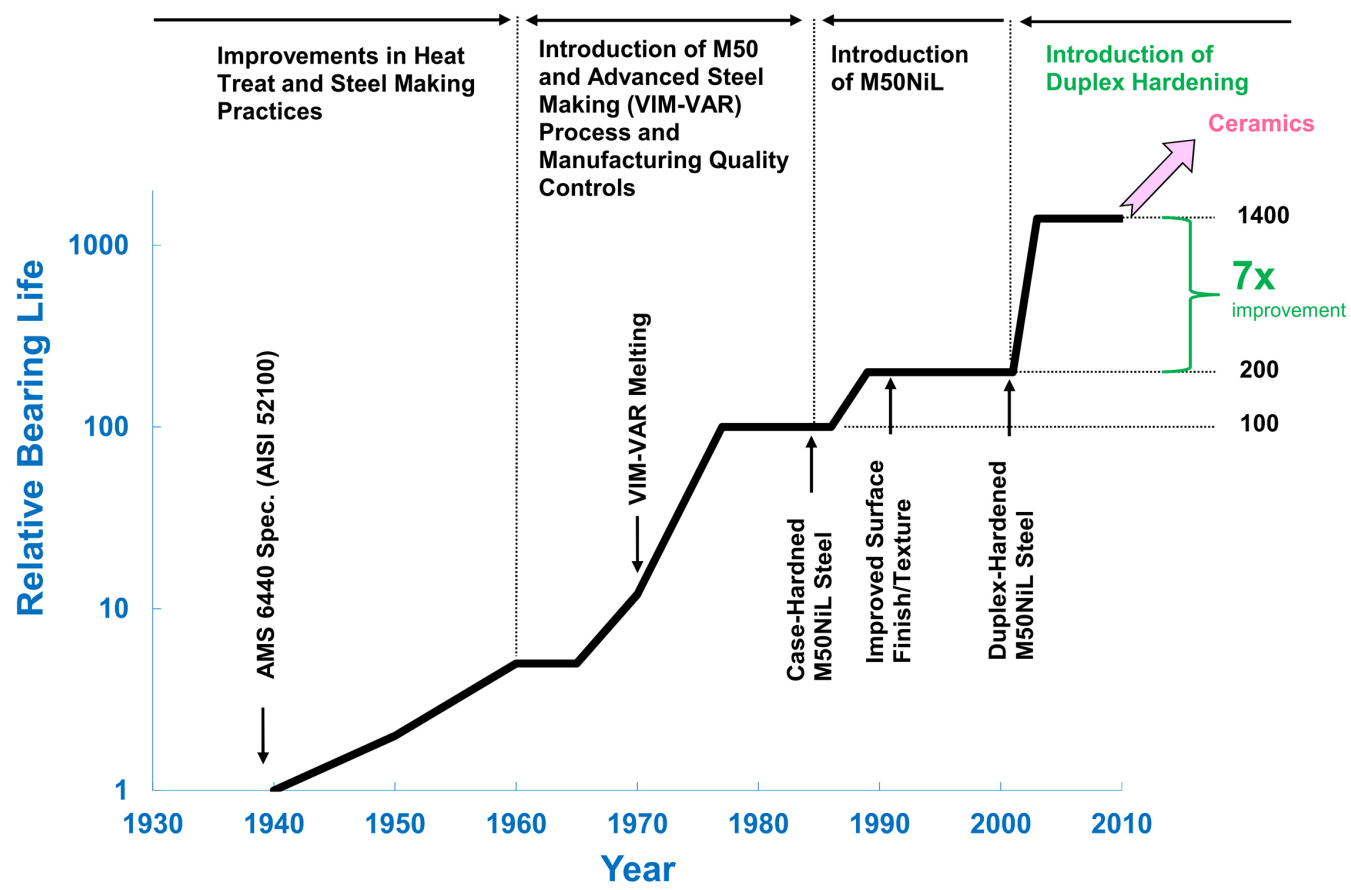

Figure 13. The development in aerospace bearing materials technology. 
initiation and propagation, fostered by M50NIL's higher fracture toughness compared to RBD or M50. Furthermore M50NiL contributes due to its soft core properties to an eased manufacturing of additional integrated features such as elastic spring beam fixations or additional cooling channels (cf. Figure 24 and Figure 26). These features significantly help to lower the total system weight and therefore reduce fuel consumption and increase mechanical efficiency (see Chapter 6). The compressive residual stress level in the hardened layer of M50NiL material is moderate, ranging from $-500 \mathrm{MPa}$ until 0 in the transition zone of case and core. Thus, the maximum depth of up to where compressive residual stresses are present depends on the case depth. These compressive residual stresses are high enough to have beneficial effects on subsurface equivalent stresses and consequently on bearing life. However, high performance bearings in modern aerospace engines and transmissions are required to operate most reliable at ever increasing operating speeds (DN-values), temperatures and loads as described above. Increased speeds translate into higher friction within the bearing rolling contacts, move the maximum subsurface towards the overrolled surface [21] and increase the risk of surface initiated fatigue due to operation in the mixed friction regime [16].

These challenges and requirements suggest the use of advanced surface engineering technologies in order to improve the operational efficiency, performance and robustness of the bearing. In spite of the more demanding operating conditions, longer service lives and higher reliability is required. While classical subsurface fatigue is rare as failure mode in aerospace bearings due to designs with Hertzian contact stresses below the fatigue stress limit [22], surface initiated fatigue is the most important failure mode in high speed aerospace bearings. Surface initiated fatigue is a consequence of either overrun hard contamination particle indentations, mounting/handling damages in the rolling contacts, corrosion pittings or mixed friction regime in the rolling contact caused by frictional heating due to high rolling/sliding speeds. Then the near surface zone of the rolling contact surfaces experiences additional superimposed stressing by the raised edges of the particle indentions or by the asperity contacts within the rolling contact.

Material strength and stressing can be improved by Duplex Hardening (DH) allowing for higher DN-values, temperatures and increased loads [23]. The almost finished bearing ring is exposed to a nitriding process in a plasma furnace. This means, before nitriding, the ring is already completely heat treated and has the properties of a standard aerospace bearing ring. The nitrogen diffuses-depending on the process parameters-into a certain depth near the surface and leads to an increased hardness and the build-up of compressive residual stresses in the nitrided layer. An optimized process also ensures that no grain boundary precipitations occur which enhances the fatigue cycle strength of the nitrided bearing ring.

Figure 14 compares the microstructure of a M50 bearing ring raceway with 
M50 (standard hardened)

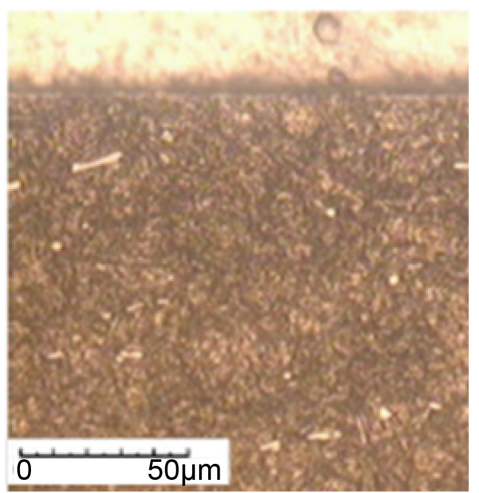

Structure M50
M50 DH (duplex hardened)

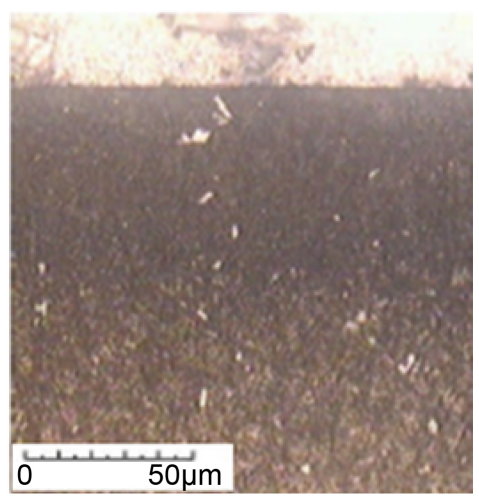

Structure M50 DH

Figure 14. Microstructure of M50 and M50 DH bearing rings.

standard heat treatment and the microstructure of a duplex hardened M50 bearing ring raceway, which experienced-in addition to the standard heat treatment-the nitriding process.

Furthermore the surface-near hardness of the nitrited ring is increased by more than $200 \mathrm{HV} 0.1$ at room temperature (Figure 15). This benefit in hardness remains also at higher temperatures [15].

Another benefit of Duplex Hardening is the development of compressive residual stresses in the nitrided layer (Figure 16). Similar to the residual stresses obtained in case carburized material, the compressive residual stress decreases towards the transition zone of nitrided layer and base material, but presents higher compressive stresses in the nitrided surface layer than in the case of conventionally carburized bearings steels.

The residual stresses can be superimposed with the stress tensor resulting from the rolling contact loading by normal (pressure) and shear (friction) stresses. Using an equivalent stress hypothesis-for instance the v. Mises maximum shear strain energy criterion - to describe the material stressing, leads to a decrease of the equivalent stress in the very near surface material depth (Figure 17), which is endangered to surface fatigue as a consequence of additional induced surface stresses [21] due to friction or hard particle indentations.

Thus, Duplex Hardening combines the benefits of increased material strength and decreased material stressing.

It should be noted that the lower surface near equivalent stresses within duplex hardened races are based on the properly adjustment of the compressive residual stress magnitude as a consequence of an optimized nitriding process. This requires a high level of Engineering Know-How especially for case carburized bearing races-such as M50NiL-which exhibit already a residual stress profiles due to carburizing before the nitriding operation is performed. The residual stresses from carburizing and from nitriding superimpose each other in the very near surface 


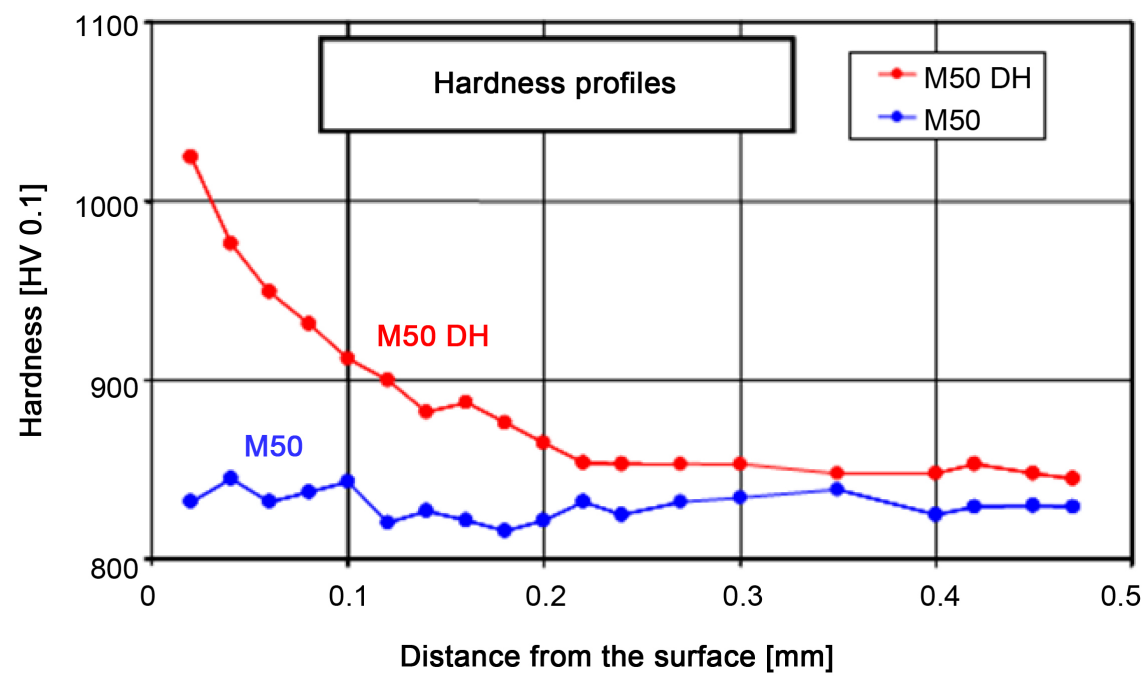

Figure 15. Hardness profiles of M50 and M50 DH bearing rings.

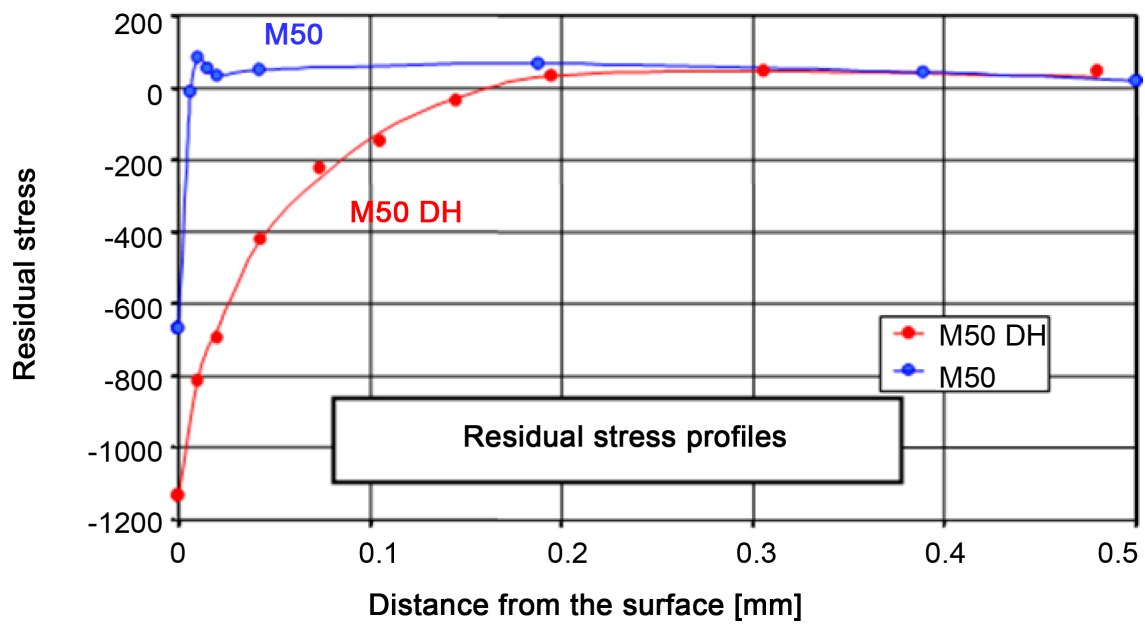

Figure 16. Residual stress profiles of M50 and M50 DH bearing rings.

area. Therefore highest care needs to be taken by limiting the superimposed compressive residual stresses to a certain maximum threshold. If this threshold is exceeded, the subsurface equivalent stress can increase again leading to a higher material stressing than for a conventional non-duplex hardened race.

In order to proof the theoretically deduced performance enhancement of duplex hardened bearings, extensive bearing life tests were conducted on FAG L17 test rigs, Figure 18.

First bearing tests had already shown that under EHD lubrication conditions and applied maximum Hertzian contact stresses of up to $4800 \mathrm{MPa}$, the duplex hardened test specimen did not fail within 200 million load cycles before the test was suspended.

To evaluate the bearing life both under mixed friction conditions and under contamination, rig tests under boundary lubrication and tests with hardness indentations were performed. These tests simulate the adverse operating conditions 


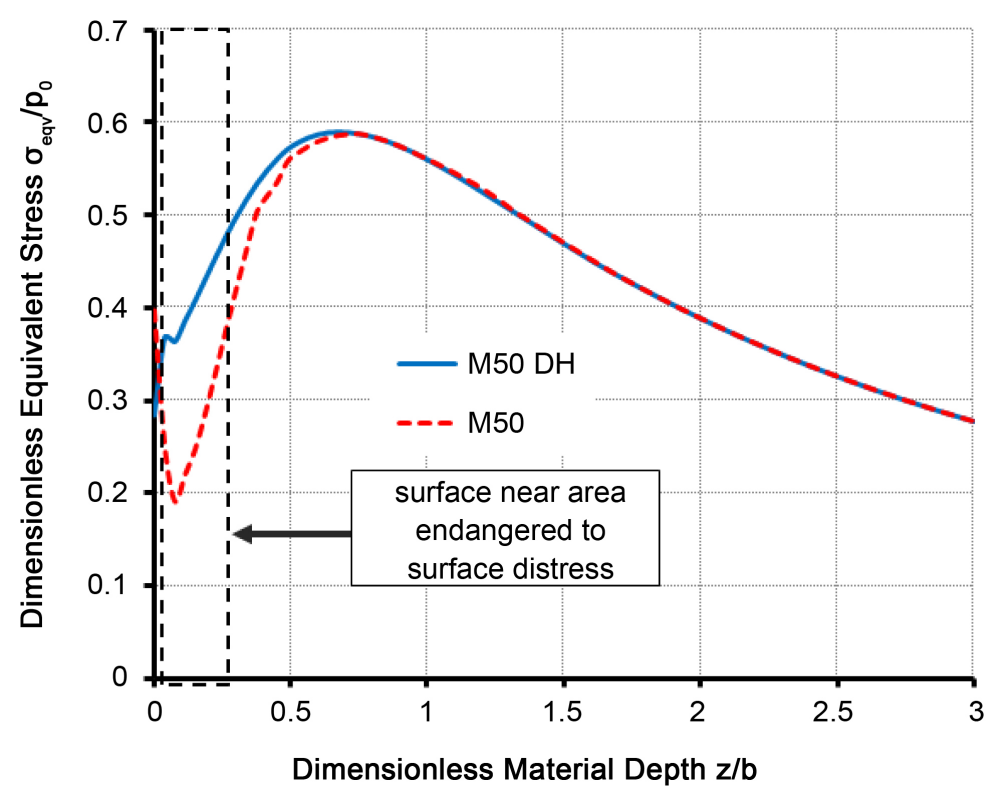

Figure 17. Dimensionless v. Mises equivalent stress for a ball bearing inner race contact; friction being absent.

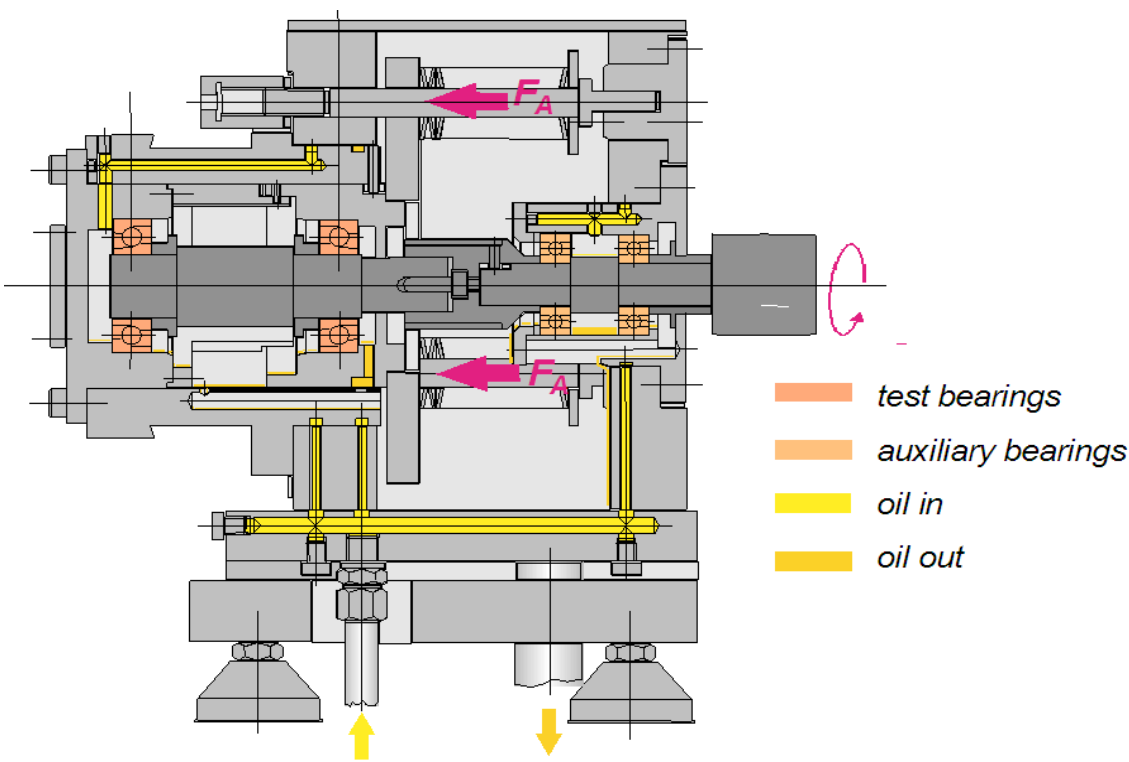

Figure 18. FAG L17 bearing test rig.

in aerospace bearings.

The test bearings running under boundary lubricating conditions (severe metal to metal contact) were loaded with a Hertzian contact stress of $2500 \mathrm{MPa}$. The oil film thickness was calculated to be $<0.1 \mu \mathrm{m}$ (a lubricating oil with a kinematic viscosity of approximately $1 \mathrm{cSt}$ at $100^{\circ} \mathrm{C}$ was used to simulate the mixed friction conditions). The shortest life was experienced by the M50 races which reached just the calculated L10 life. The M50NiL races lasted approximately 5 times the calculated L10 life. Despite the intense metal to metal contact the duplex hardened M50 (DH) and M50NiL (DH) races demonstrated the longest life by reaching 
a tested lifetime of 1500 hours before the tests were suspended. Figure 19 shows the life test results of baseline and duplex hardened bearings under mixed friction conditions.

The test conditions for the test series with the hardness indentations in the bearing ring raceway were kept the same as for the test series under boundary lubrication conditions, except that the test races were predamaged by Rockwell indentations in the load path of the bearing inner race and that the standard jet engine oil with a kinematic viscosity of $5 \mathrm{cSt}$ at $100^{\circ} \mathrm{C}$-in order to gain full EHD lubrication-was used.

Figure 20 shows the advantages of duplex hardened bearings also under contaminated operating conditions. While the M50 baseline reaches predicted L10

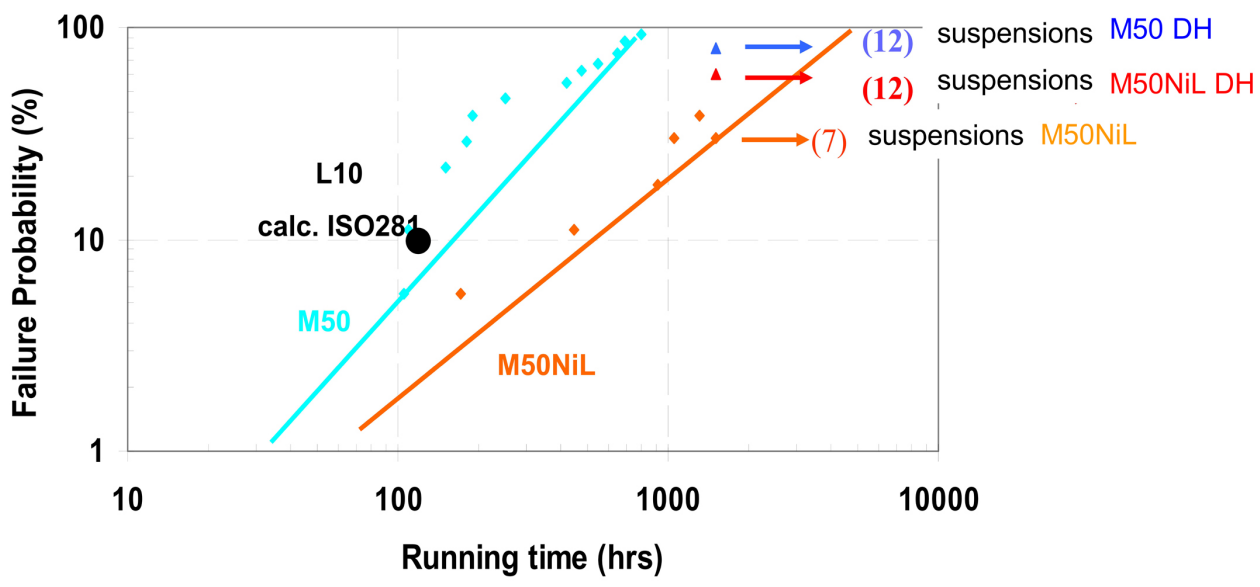

\section{$\mathrm{L} 17, \mathrm{p}_{\mathrm{o}}=2500 \mathrm{MPa}$ \\ $\mathrm{n}=12000 \mathrm{rpm}$, Mobil Velocite 3 \\ Rolling Contact Fatigue life under boundary lubrication \\ Oil: $\mathrm{K}=0,14 ; \mathrm{T}_{\mathrm{OR}}=85^{\circ} \mathrm{C}$}

Figure 19. Life of duplex hardened and conventional bearings; tested under boundary lubrication conditions.

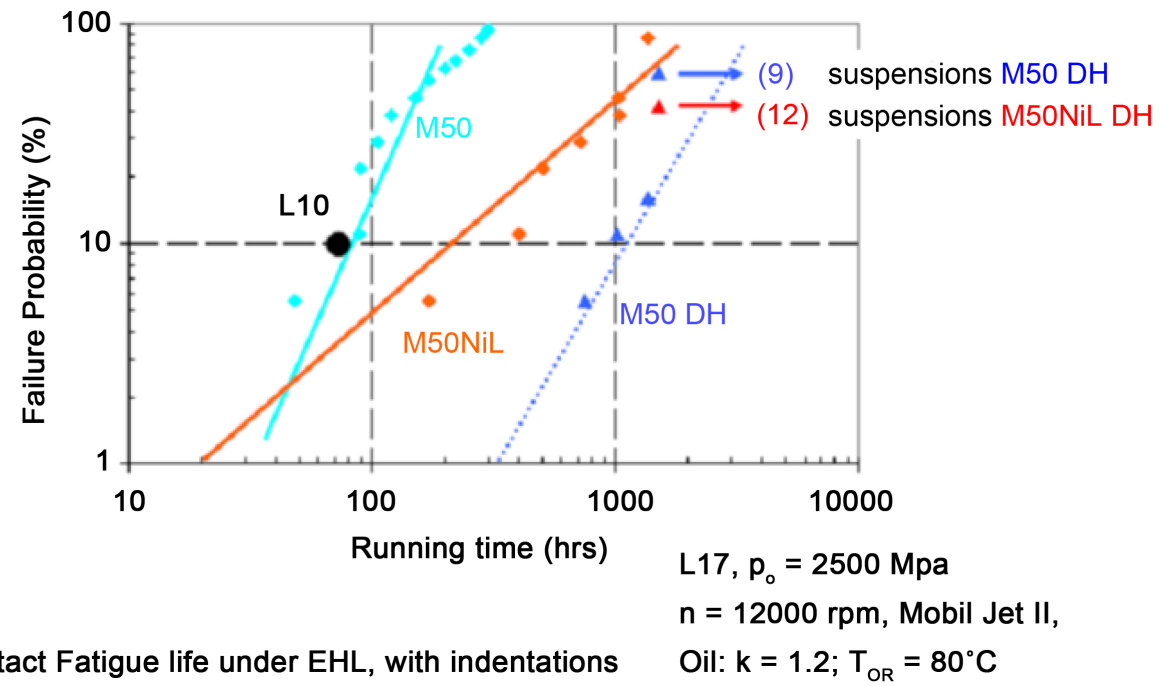

Figure 20. Life of duplex hardened and conventional bearings; tested with Rockwell indentations. 
life and the M50NiL has about a 5 times higher life than M50, only three M50 duplex hardened bearings failed and none of the 12 tested M50NiL duplex hardened bearings failed.

Due to the advantages of high compressive stresses beneath the rolling contact surfaces and the high (hot) hardness, Duplex Hardening increases the bearing life both under full EHL, mixed friction and contaminated conditions.

This means Duplex Hardening is an appropriate method to improve the performance and robustness of bearings facing extreme operating conditions, such as high speeds, high loads and/or bearings that have to deal with adverse lubricating conditions. This is especially required for future aircraft gas turbines with increased efficiency running at higher speeds and temperatures and which require higher thrust to weight ratio bearings.

Silicon nitride is used as rolling element material (Figure 21) in so called hybrid bearings achieving further weight reductions of more than $40 \%$ compared to conventional steel elements.

Beyond that, hybrid bearings have been proven to generate less heat and therefore operate at lower bearing temperatures [24] [25]. This results in both increased bearing system efficiency and reliability. The performance characteristics of hybrid bearings compared with all-steel bearings are shown in Figure 22.
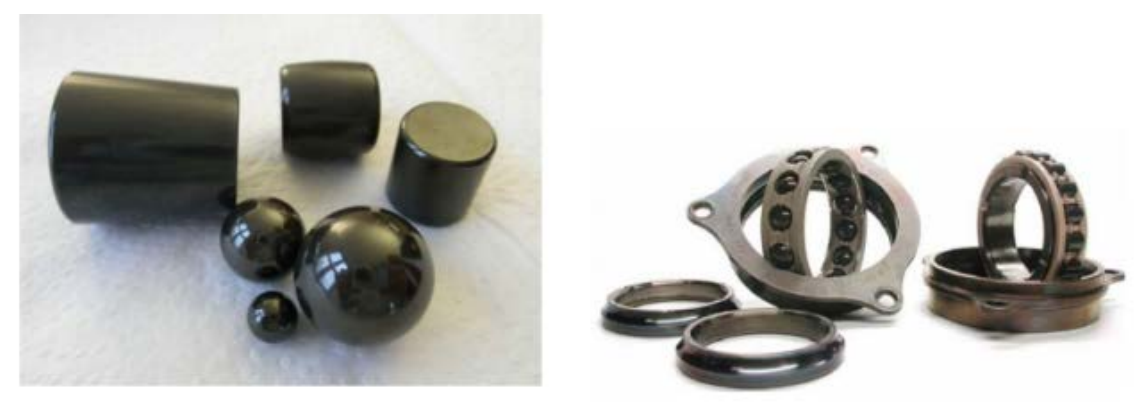

Figure 21. Ceramic rolling elements (left) and hybrid rolling bearings (right).

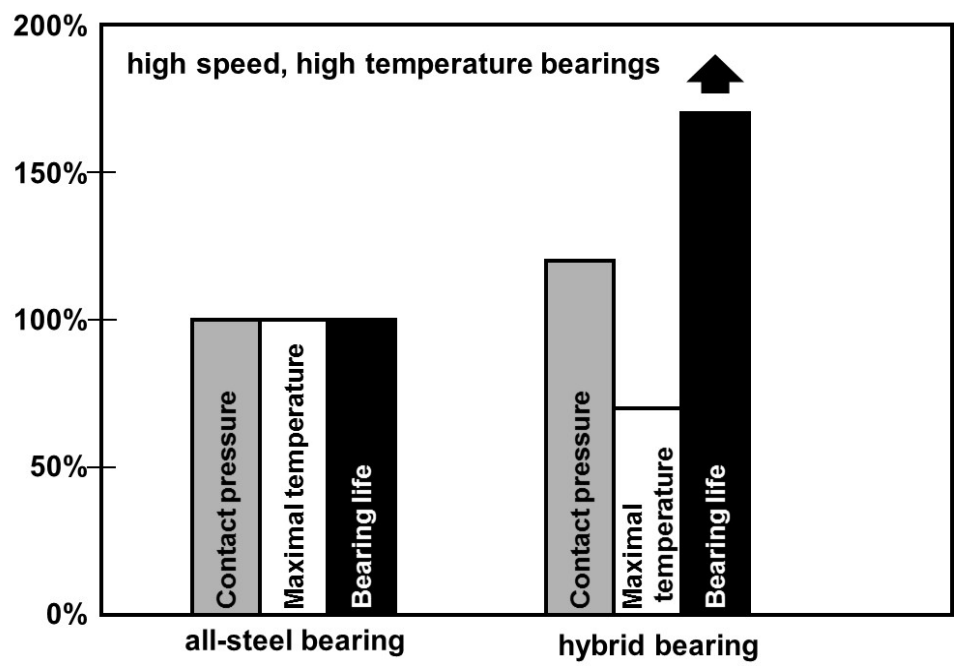

Figure 22. Performance characteristics of all-steel and hybrid bearings. 
For aerospace bearing applications operating under harsh environmental conditions, the corrosion resistant steel Cronidur 30 (Streit [26]) was developed. For instance Cronidur 30 bearing steel was introduced as raceway material for the rolling bearings-running in liquid hydrogen-applied in the High Pressure Fuel Turbopump (HPFTP) of the Space Shuttle Main Engine (SSME) as well as for swash plate bearings in helicopters, to mention a few applications. In combination with ceramic rolling elements they contribute to significant weight savings in helicopter rotor heads.

Surface platings such as silver and manganese phosphate are state of the art for aerospace bearing cages. These platings increase the fail-safe properties in the unlikely event of oil-off or oil-interruption operating conditions. Physical Vapor Deposition (PVD) coatings such as titanium nitride (TiN) are used to improve wear resistance. Throughout the last decades Diamond Like Carbon (DLC) coatings were developed for the automotive industry showing a tremendous success reducing friction and increasing wear resistance. Recently DLC's were also introduced for aerospace bearing components. One application example is a DLC on the roller end face aiming to increase the roller end wear resistance.

\section{Aerospace Bearing Design}

Besides material, the advanced design of aerospace bearing systems contributes considerably to reduced bearing and system weight, higher performance and efficiency as well as life and reliability as shown in this chapter.

Furthermore durability, robustness and reliability, the system and/or life cycle cost play an important role in the design of aerospace main shaft and gearbox bearings. In aerospace applications, the influence from the design on the total product and system cost can be estimated with approximately $70 \%$ of the total product cost. The consequence is integrated bearing solutions in order to achieve the most cost and weight effective solutions. The aerospace bearing integration scale increased-driven by the aforementioned factors-especially throughout the last 20 years. The increasing trend for functional integration is shown in Figure 23. Starting from catalog-type bearings in the 1960s aircraft engine main shaft bearings developed into highly integrated shaft/bearing modules in the late 1990s. Besides significant reductions in system weight and power loss, the integrated bearing solutions represent increased system reliability, i.e. less maintenance and overhaul. Therefore integrated bearing designs represent a win-win situation for the bearing supplier, the engine/gearbox/system manufacturer, and the environment. The OEM has the advantages of cost savings by less overall weight, less maintenance intervals, reduced tolerance stack-ups, functional benefits and a reduced number of suppliers accompanied by significant reduced greenhouse gas system emissions.

In the first integration stage for main shaft bearings, flanged outer rings, puller grooves, and under-race lubrication features were combined in one bearing. In the beginning of the 1990s additional functional features such as elastic fixations ("squirrel cage") to the housing including fixation nuts, grooves in the 


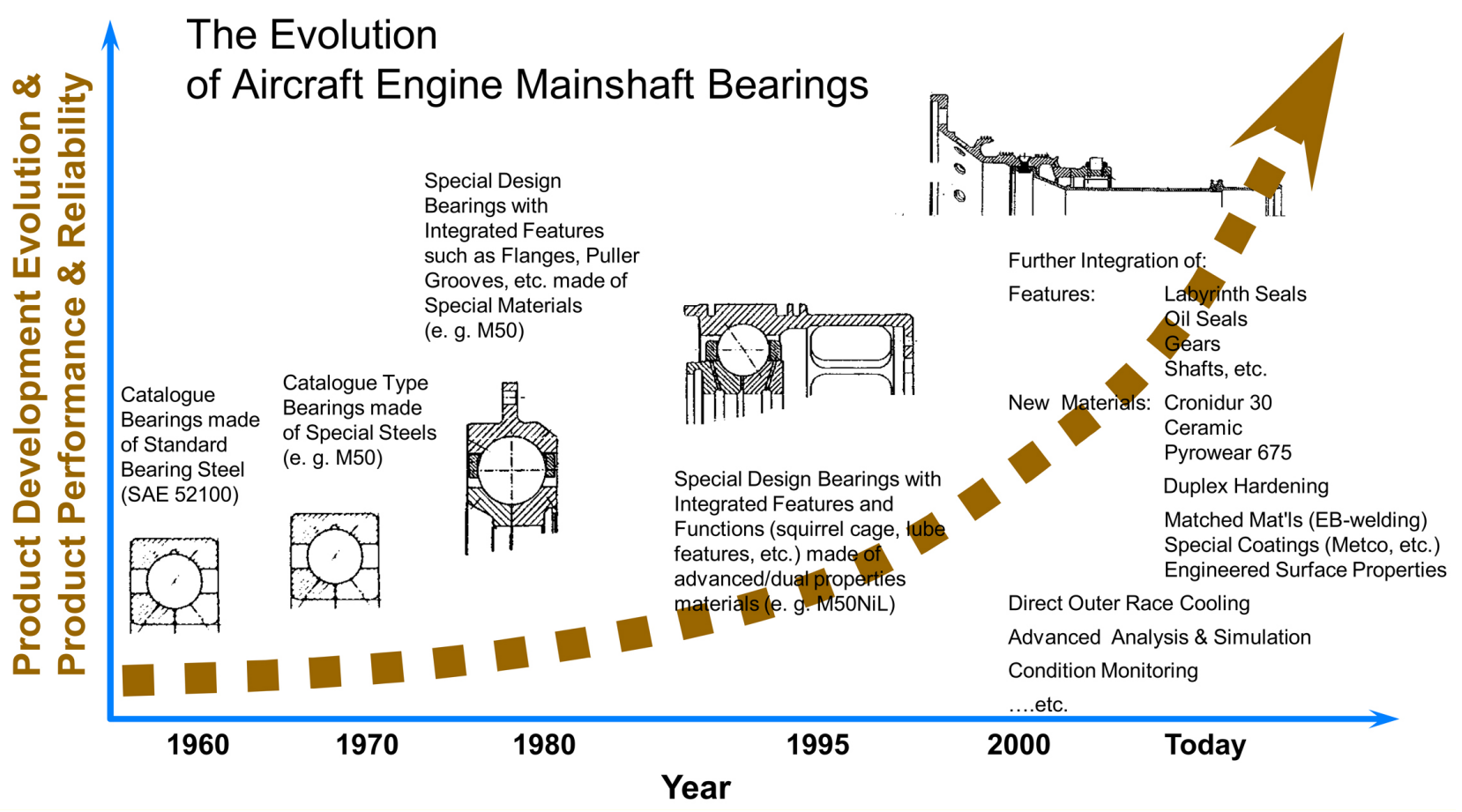

Figure 23. Progress of integrated aerospace bearing designs.

bearing outer diameter allowing for squeeze film damping between outer ring and housing and anti-rotation lugs were added to the bearing (2nd integration stage, see Figure 24, left). Integration of theses functional features offers system weight savings of up to $30 \%$ compared to a conventional design with separate parts for elastic fixation and squeeze film damping.

The right hand picture in Figure 24 shows an example of an integrated aircraft engine main shaft-bearing-system, comprised of shaft, bearing, damper, and seals representing the 3rd stage of main shaft bearing integration. Both the low pressure and the high pressure shaft are made out of a nickel-superalloy and are electron beam welded with the case hardened roller bearing inner rings. This combines the properties of the high temperature strength of the shafts and the rolling contact fatigue of the bearing rings. The outer rings, made out of M50 aerospace bearing steel, are integral with a squeeze film damper, i.e. a thin oil film between housing and outer ring, bounded by piston rings. Both bearings are located in the same bearing chamber sealed with labyrinths.

Another example is the integrated planetary gear in the outer ring of a spherical roller bearing as shown in Figure 25. The bearing is installed in the planetary reduction gearbox of a turboprop engine. It combines the gear and bearing functions and therefore represents a significant weight reduction compared to a conventional design with separate gear and bearing. Also, the integrated design has the advantage, besides a reduced cross section, that the outer race can be ground to the datum of the gear pitch diameter which offers reduced radial runout values, hence improved gear meshing and an overall reduced stressing.

As described above, aircraft engine bearing operating conditions like rotational 

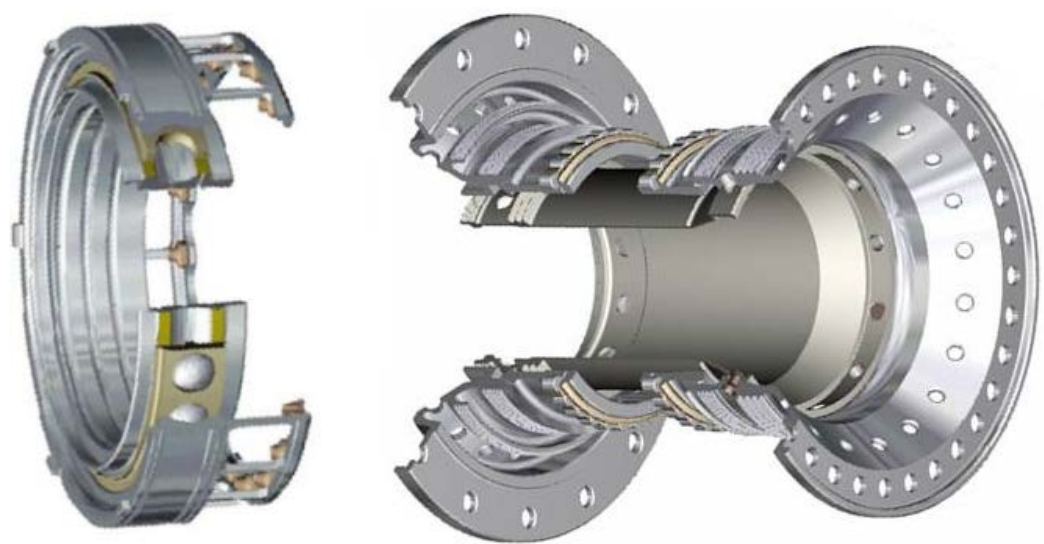

Figure 24. Main shaft ball bearing (2nd integration stage), left and integrated roller bearing main shaft design (3rd integration stage), right.

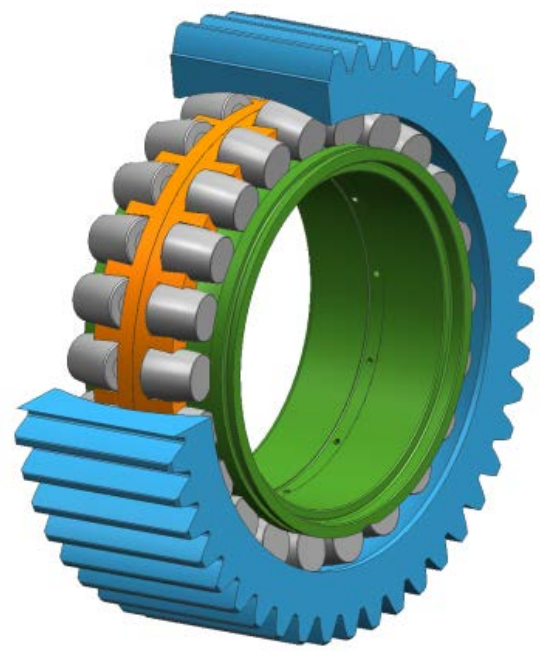

Figure 25. Spherical roller bearing with integrated geared outer ring.

speeds, loads and temperatures increased continuously over the last decades. This is one reason why today's advanced aircraft engines operate with the highest efficiencies in gas turbine history. The speed index DN has a significant effect on the bearing temperatures. Accommodating ever increasing speed indices, the oil volume flow needs to be increased in order to maintain the bearing temperatures below the critical thresholds. Beyond these thresholds both the bearing steel components and the lubricant properties deteriorate and additional stressing is induced in the rolling contacts, i.e. a loss of material cycling strength is accompanied by higher surface normal and shear stress in the rolling contact. Furthermore lubricant evaporation losses increase disproportionately, viscosity and density behavior is degraded and oil coking occurs until the flash temperature is reached. High speed aircraft engine bearings are typically lubricated by the "under-race" lubrication method, i.e. the oil is routed by the centrifugal force through drilled holes in the shaft and/or grooves in the bearing inner rings to the bearing inte- 
rior. Compared with the "side-jet" lubrication method-where the oil jet aims at the rolling elements from one or both bearing sides-which is used for bearing running at moderate speeds, the "under-race" lubrication eliminates windage losses and provides a more precise and targeted oil supply resulting in lower bearing temperatures. However, as consequence of the radial oil flow due to centrifugal forces the bearing inner ring temperatures are significantly lower than the outer ring temperatures.

While only a very minor portion of the supplied oil is needed for lubrication, the major portion is required to cool the bearing. Therefore a high amount of power due to oil churning is lost within the bearing, especially under high speed operating conditions as typical for aircraft engine main shaft bearings. A solution to this dilemma is provided by the so called "Direct Outer Ring Cooling Concept". Here, a helical cooling channel is machined in the outer ring outer diameter (Figure 26). The heat from the bearing outer ring is transferred to the oil flowing in the outer ring cooling channel and therefore results in a lower outer ring temperature (Figure 27). Consequently a lower amount of oil supplied by under-race is necessary in order to maintain the same or lower ring temperature as for the conventional design. The lower oil quantities result in reduced power losses due to churning (Figure 27) and the lower bearing temperatures increase the minimum contact film thickness and the material endurance strength [16] [22]. Thus, the bearing efficiency, reliability, and performance are enhanced. The ball bearing shown in Figure 26 (right) was tested on the FAG AN62 high speed full scale test rig. The ball bearing was purely axially loaded in a thrust range of $40 \mathrm{kN}$ to $80 \mathrm{kN}$. The rotational speed has been varied between $8000 \mathrm{rpm}$ and $17,000 \mathrm{rpm}$. Calculating the product of the bearing's pitch diameter and the rotational speed (speed index DN) leads to values of up to $2.8 \times 10^{6} \mathrm{~mm} / \mathrm{min}$, which is in the typical range of modern jet engine rolling bearings (see Figure 8). The nominal bearing under-race oil flow was varied between 5 and $121 / \mathrm{min}$ and the cooling oil flow through the outer channel was varied between 0 and $10 \mathrm{l} / \mathrm{min}$. Axial loads and rotational speeds result in a Hertzian pressure range
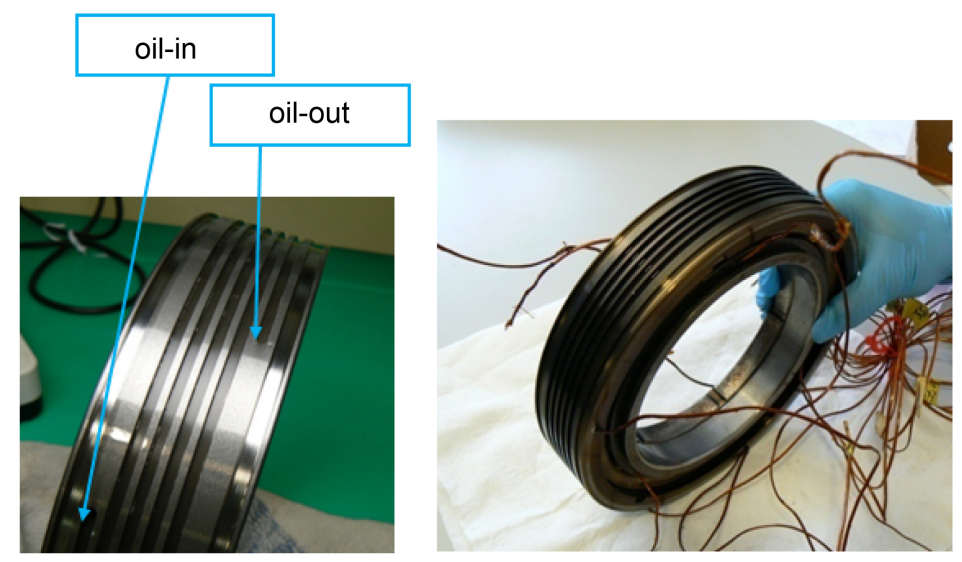

Figure 26. Cooling channel in the outer ring outer diameter (left) and rig tested ball bearing (right). 


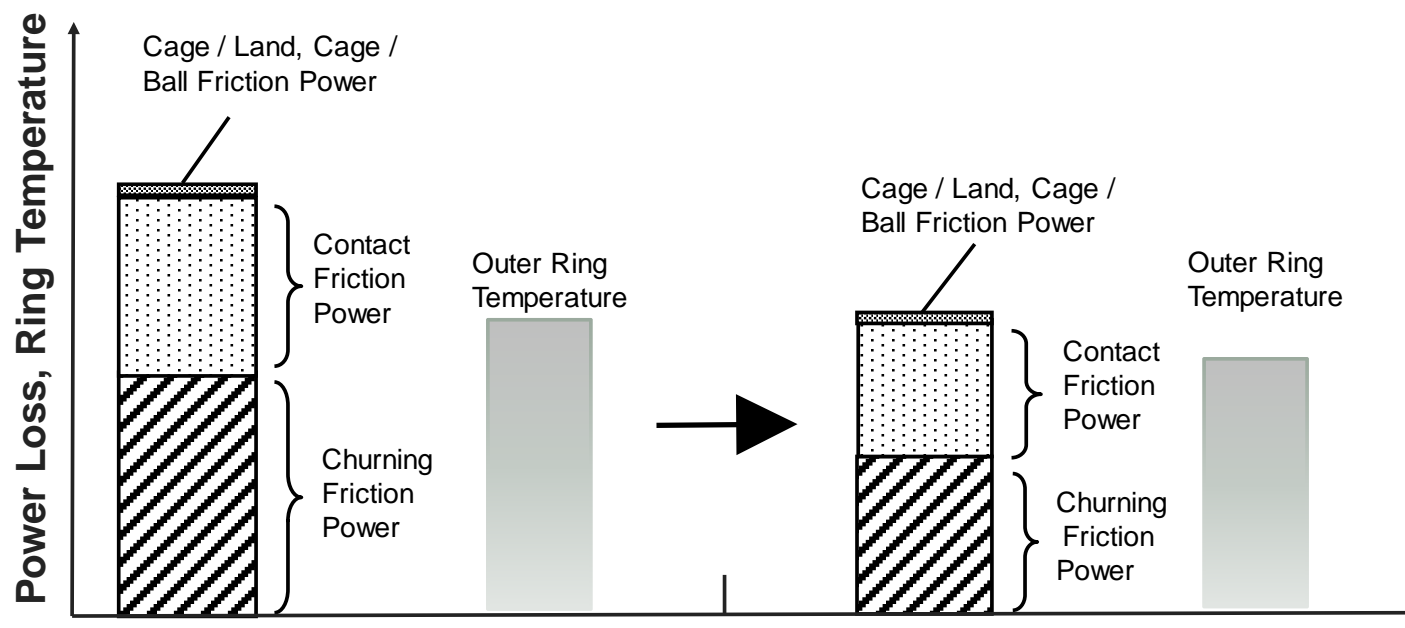

Conventional Ball Bearing

Ball Bearing with Direct Outer Ring Cooling
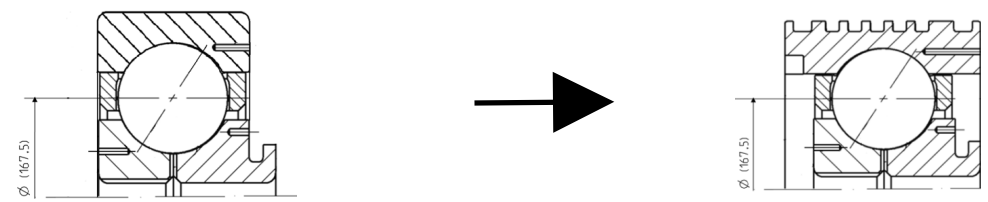

Figure 27. Influence of direct outer ring cooling on bearing power loss and temperature.

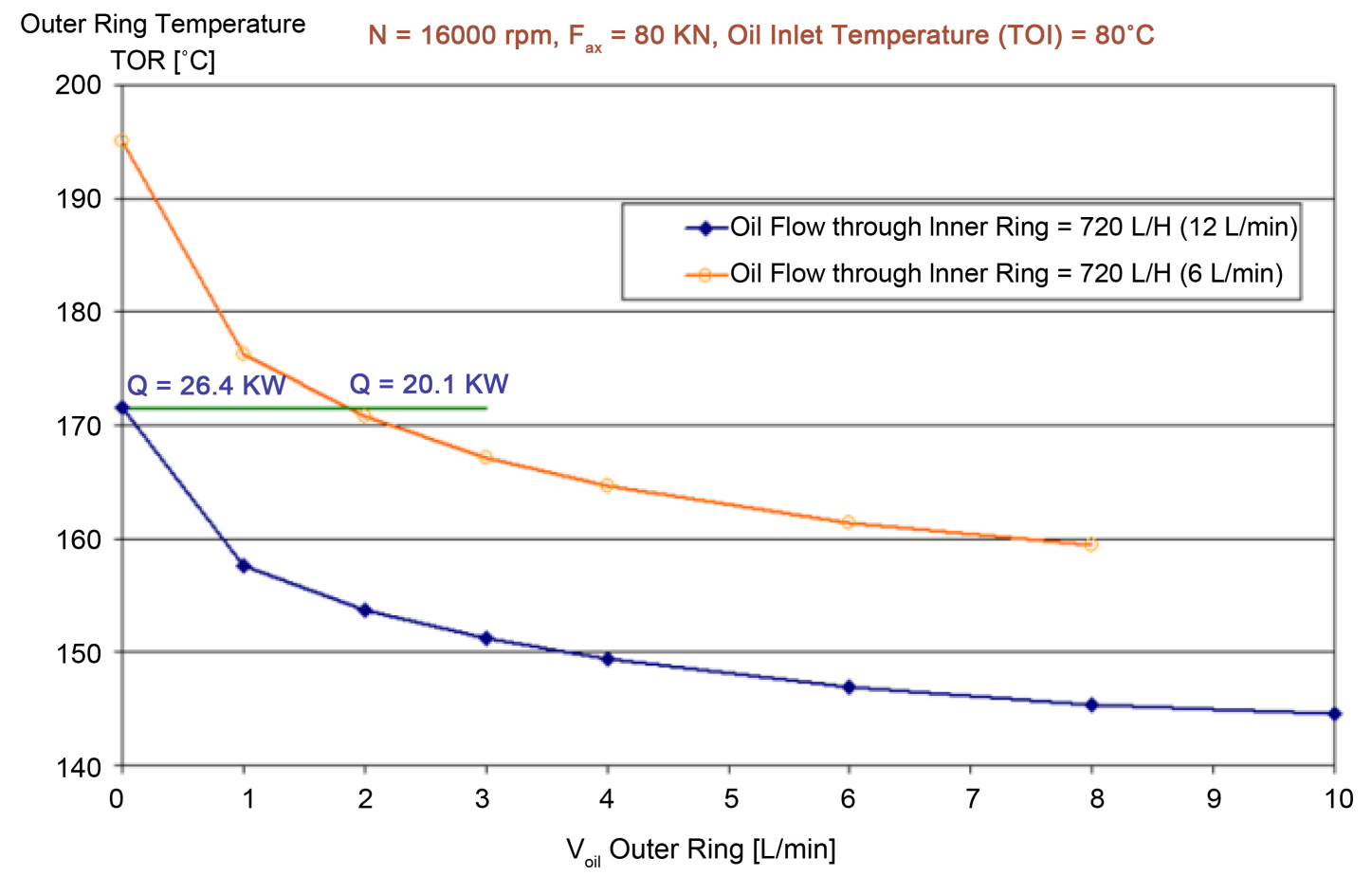

Figure 28. Outer ring temperature and power loss for various outer ring channel oil flows and two different "under-race" oil flows.

between 1480 and $2470 \mathrm{MPa}$ on the inner race and 1340 and $2220 \mathrm{MPa}$ on the outer race depending on inner race and outer race temperature for each single test point. The lubricant used in this investigation meets the requirements of MIL-PRF 
23699.

The comprehensive test program comprised measurements of inner and outer ring temperature (both on the loaded and unloaded sides), cooling channel oil in and oil out temperatures, bearing chamber oil out temperature, the oil temperature close to the cage side faces, and the bearing oil out flow. In addition the bearing power loss was measured by a torque meter.

It is desirable to cool the outer ring to a certain temperature at high $\mathrm{DN}$ values. It is reasonable to define the maximum inner ring temperature as this threshold in order to obtain the same thermal loading on the inner raceway and outer raceway, respectively. Using this definition, the oil volume flow through the outer ring channel can be adjusted. Furthermore, an optimized combination of under-race oil flow and cooling channel oil flow can be adjusted in order to obtain the same outer ring temperature as for the conventional bearing. This is illustrated by Figure 28. The outer ring temperature for the conventional ball bearing is $172^{\circ} \mathrm{C}$ for an under-race oil flow of $12 \mathrm{~L} / \mathrm{min}$. The same temperature can be adjusted with an under-race oil flow of $6 \mathrm{~L} / \mathrm{min}$ and a cooling channel oil flow of $2 \mathrm{~L} / \mathrm{min}$ using the Direct Outer Ring Cooling Design. Consequently, only 50\% of the oil quantity of the conventional bearing is churned within the bearing resulting in a power loss reduction of $6.3 \mathrm{~kW}$, representing $24 \%$ power loss reduction compared to the conventional bearing. The total oil quantity saving for both the cooling channel and the under-race oil flow is $4 \mathrm{~L} / \mathrm{min}$ (33\%).

It is also shown in Figure 28 that low oil quantities through the outer ring cooling channel allow for significant ring temperature reductions, i.e. a ring temperature reduction of $\Delta \mathrm{T}=25 \mathrm{~K}$ is achieved by only $2 \mathrm{~L} / \mathrm{min}$ oil flow through the outer ring cooling channel. In [27] further investigation results are presented. Amongst others in this paper it is shown that the cooling channel is efficient for a broad range of rotational speeds and axial load, and that the cooling concept is suitable for high oil inlet temperatures as well. Beyond that the direct outer ring cooling concept offers numerous benefits to the overall system. Due to the lower oil- and bearing-temperatures less heat transfer is required by the air/oil- and kerosene/oil-coolers. Furthermore lower temperatures contribute to an improvement in material fatigue strength and therefore increase bearing life and reliability. It was shown in [25] that the combination of direct outer ring cooling, ceramic balls and integrated squeeze film damping enables speed indices above 4 Mio $\mathrm{mm} / \mathrm{min}$ supporting the trend to high speed cores of next generation aircraft gas turbines.

In addition to the reduced bearing power loss, smaller oil pumps and oil supply systems are required with lower "under-race" oil quantities. As a consequence of the reduced system weight and the reduced "under-race" oil flow, the mechanical efficiency of both the bearing and the engine is increased. Thus, the engine fuel consumption and with it the engine emissions are reduced. Assuming that the direct outer ring cooling concept is applied on the aircraft engine high pressure spool ball bearing and considering a $6 \mathrm{~kW}$ power loss reduction per bear- 
ing, approximately 6 metric tons of kerosene can be saved per year and engine if this engine runs 12 hours a day. Consequently savings of approximately 6000 metric tons of kerosene per year can be achieved for an airplane fleet with 1000 engines. Estimating the total quantity of engines in service to 40,000 , the amount of kerosene saved per year would be circa 230,000 metric tons. This equals a yearly $\mathrm{CO}_{2}$ reduction of $18,18,000$, and 720,000 tones for one, 1000, and 40,000 aircraft engines respectively. It is obvious that the reduction of system weight and fuel consumption translates into significant reductions in total system and operating cost.

Besides integrated bearing ring designs, the bearing cage design is continuously optimized in order to contribute to bearing weight and performance improvements. For example, the introduction of milled cage pockets for cylindrical roller bearings with optimized pocket radii and undercuts enables an odd number of rollers and therefore optimized bearing weight [28].

\section{Conclusions}

The fast growing aerospace market represents a major challenge for the aerospace industry. High efficient components and systems and all-new aircrafts are required in order to comply with ecological and economical demands.

The mechanical efficiency of aircraft engines and rotorcrafts is one important key to achieve the goals set by politics and OEM's. As rolling element bearing systems are one of the most important machine elements strongly influencing the system efficiency, the requirements for high efficient aircraft translate into higher bearing speeds, loads, temperatures and decreased power loss at simultaneously increased reliability. To face these challenges, further developments especially focusing on bearing efficiency are required in rolling bearing analysis, materials, surface technology and (system) design, although enormous progress was made throughout the last decades.

It was shown in the previous chapters that quasi-static calculation methods already include a high level of system integration considering shaft, housing and contact mechanics. However, for future friction optimized solutions, EHL and multi-body simulations will become more important in rolling bearing design.

New materials and heat treatment/surface technologies were developed recently and are currently being developed in order to comply with the requirements for higher speeds, loads, and temperatures. As case hardened high temperature bearing steels for raceways represent an intermediate solution for high speed bearings in aircraft engines, duplex hardened raceways will be required for high-DN aircraft engine bearings. Furthermore, high expectations on further friction reduction and high speed capability are connected to the use of silicon nitride rolling elements, i.e. hybrid bearings on aircraft engines main shafts. The combination of duplex hardened raceways and ceramic rolling elements represents both increased raceway strength and higher speed capability and will be the preferred design option for high speed aircraft engine bearings in the next two decades. Advanced coatings such as DLC's can be a useful addition to the materials described above 
helping to increase reliability and efficiency.

Higher integrated bearing designs, such as shaft/bearing and gear/bearing modules contribute significantly to reduced total system weight and therefore reduced fuel consumption and greenhouse gas emissions. Advanced cooling systems such as the Direct Outer Ring Cooling Concept are required to directly influence the bearing power loss, performance and reliability and have direct effects on system weight, oil and fuel consumption and therefore on greenhouse gas emissions. Each bearing and oil system component is subject to ongoing developments for weight and efficiency optimized designs.

The progress in analysis, design, and materials already supported significantly efficiency and reliability improvements. The combination of all these efforts shows tremendous potential for efficiency and reliability improvements of more than $50 \%$ compared to today's state of the art aerospace bearings and therefore will contribute to overcome the challenges of the aerospace market within the next decades.

\section{References}

[1] Stevenson, D.S., Doherty, R.M., Sanderson, M.G., Collins, W.J., Johnson, C.E. and Derwent, R.G. (2004) Radiative Forcing from Aircraft $\mathrm{NO}_{x}$ Emissions: Mechanisms and Seasonal Dependence. Journal of Geophysical Research: Atmospheres, 109, D17307. https://doi.org/10.1029/2004JD004759

[2] Penner, J.E., Lister, D.H., Griggs, D.J., Dokken, D.J. and McFarland, M. (1999) Aviation and the Global Atmosphere. A Special Report of IPCC Working Groups I and III, 373, Cambridge University Press, Cambridge, UK.

[3] Gaus, M., Isaksen, I.S.A., Lee, D.S. and Søvde, O.A. (2006) Impact of Aircraft $\mathrm{NO}_{x}$ Emissions on the Atmosphere-Tradeoffs to Reduce the Impact. Atmospheric Chemistry and Physics, 6, 1529-1548. https://doi.org/10.5194/acp-6-1529-2006

[4] Rap, A., Forster, P.M., Haywood, J.M., Jones, A., Boucher, O. (2010) Estimating the Climate Impact of Linear Contrails Using the UK Met Office Climate Model. Geophysical Research Letters, 37, L20703. https://doi.org/10.1029/2010GL045161

[5] Haywood, J.M., Allan, R.P., Bornemann, J., Forster, P.M., Francis, P.N., Milton, S., Rädel, G., Rap, A., Shine, K.P. and Thorpe, R. (2009) A Case Study of the Radiative Forcing of Persistent Contrails Evolving into Contrail-Induced Cirrus. Journal of Geophysical Research: Atmospheres, 114, D24201.

https://doi.org/10.1029/2009JD012650

[6] European Commission (2011) Flightpath 2050-Europe's Vision for Aviation. Report of the High Level Group on Aviation Research.

[7] Jemitola, P.O. (2012) Conceptual Design and Optimization Methodology for Box Wing Aircraft. PhD Thesis, Cranfield University, UK.

[8] Bottoni, C. and Scanu, J. (2004) Preliminary Design of a 250 Passenger Prandtl Plane Aircraft. Graduating Thesis, University of Pisa, Pisa.

[9] Harris, T.A. (2001) Rolling Bearing Analysis. 4th Edition, John Wiley \& Sons, Inc., Hoboken.

[10] Gloeckner, P. (2013) The Influence of the Raceway Curvature Ratio on Power Loss and Temperature of a High-Speed Jet Engine Ball Bearing. Tribology Transactions, 56, 27-32. https://doi.org/10.1080/10402004.2012.725123 
[11] Forster, N., Svendsen, V., Givan, G., Thopmpson, K., Dao, N. and Nicholson, B. (2011) Parametric Testing and Heat Generation Modeling of 133-mm Bore Ball Bearings: Part I-Results with Metal Rolling Elements. Tribology Transactions, 54, 315-324. https://doi.org/10.1080/10402004.2010.542276

[12] Gupta, P.K. (1984) Advanced Dynamics of Rolling Elements. Springer, Berlin. https://doi.org/10.1007/978-1-4612-5276-4

[13] Degtiarev, A., Lenssen, S., Vesselinov, V. and Bakolas, V. (2009) Determination of Fatigue Loads of Complex Systems. 64th STLE Annual Meeting, Lake Buena Vista, FL, 17-21 May 2009.

[14] Hamrock, B.J. and Dowson, D. (1976) Isothermal Elastohydrodynamic Lubrication of Point Contacts. Part III-Fully Flooded Results. Journal of Lubrication Technology, 99, 264-276.

[15] Gloeckner, P. and Ebert, F.-J. (2010) Micro-Sliding in High-Speed Aircraft Engine Ball Bearings. Tribology Transactions, 53, 369-375.

https://doi.org/10.1080/10402000903312364

[16] Gloeckner, P., Sebald, W. and Bakolas, V. (2009) An Approach to Understanding Micro Spalling in High Speed Ball Bearings Using a Thermal Elastohydrodynamic Model. Tribology Transactions, 52, 534-543. https://doi.org/10.1080/10402000902774267

[17] Salpistis, C., Mihailidis, A., Drivakos, N. and Gatsios, S. (2006) Experimentally Obtained Solid Contact Time Curves as Criterion of the EHL Performance of Rough Surfaces. The 2 nd International Conference "Power Transmission 06", Novi Sad, 25-26 April 2006, 347-350.

[18] Ebert, F.J. and Poulin, P. (1995) The Effect of Cleanliness on the Attainable Bearing Life in Aerospace Applications. Tribology Transactions, 38, 851-856. https://doi.org/10.1080/10402009508983479

[19] Boehmer, H.J., Ebert, F.J. and Trojahn, W. (1991) M50NiL Bearing Material-Heat Treatment, Material Properties and Performance in Comparison with M50 and RBD. 46th STLE Annual Meeting, Montreal, Canada, 29 April-2 May 1991, Preprint No. 91-AM-3G-2

[20] Broszeit, E. and Zwirlein, O. (1986) Internal Stresses and Their Influence on Material Stresses in Hertzian Contacts-Calculations with Different Stress Hypothesis. Journal of Tribology, 108, 387-393. https://doi.org/10.1115/1.3261212

[21] Schlicht, H. and Zwirlein, O. (1980) Werkstoffanstrengung bei Wälzbeanspruchung-Einfluß von Reibung und Eigenspannungen. Materialwissenschaft und Werkstofftechnik 11, 1-14. https://doi.org/10.1002/mawe.19800110104

[22] Boehmer, H., Loesche, T., Ebert, F.J. and Streit, E. (1999) The Influence of Heat Generation in the Contact Zone on Bearing Fatigue Behavior. Journal of Tribology, 121, 462-467. https://doi.org/10.1115/1.2834090

[23] Streit, E., Brock, J. and Poulin, P. (2006) Performance Evaluation of "Duplex Hardened" Bearings for Advanced Turbine Engine Applications. Journal of ASTM International, 3.

[24] Ebert, F.-J. (1990) Performance of Silicon Nitride $\left(\mathrm{Si}_{3} \mathrm{~N}_{4}\right)$ Components in Aerospace Bearing Applications. Proceedings of the Gas Turbine and Aeroengine Congress and Exposition, The American Society of Mechanical Engineers, Brussels, 11-14 June 1990, 90-GT-166.

[25] Gloeckner, P., Martin, M. and Flouros, M. (2017) Comparison of Power Losses and Temperatures between an All-Steel and a Direct Outer Ring Cooled, Hybrid 133 mm Bore Ball Bearing at Very High Speeds. Tribology Transactions, 60, 1148-1158. https://doi.org/10.1080/10402004.2016.1262930 
[26] Streit, E., Trojahn, W., Chin, H.A. and Ehlert, D. (1999) Progress in Bearing Performance of Advanced Nitrogen Alloyed Stainless Steel, Cronidur 30. Materialwissenschaft und Werkstofftechnik, 30, 605-611.

https://doi.org/10.1002/(SICI)1521-4052(199910)30:10<605::AID-MAWE605>3.0.C $\mathrm{O} ; 2-\mathrm{V}$

[27] Gloeckner, P., Dullenkopf, K. and Flouros, M. (2011) Direct Outer Ring Cooling of a High Speed Jet Engine Mainshaft Ball Bearing. Journal of Engineering for Gas Turbines and Power, 133, 062503-1-7. https://doi.org/10.1115/1.4002355

[28] Glöckner, P. (2009) Advanced Bearing Technologies for Aerospace Power Systems. Proceedings of the 3rd International Conference "Power Transmission'09", Chalkidiki, 427-434. 